\title{
ERRADICACIÓN DEL TRABAJO FORZOSO: PERSPECTIVAS DESDE GINEBRA, ESTRASBURGO Y SAN JOSÉ
}

\author{
ERADICATION OF FORCED LABOR: \\ PERSPECTIVES FROM GENEVA, \\ STRASBOURG AND SAN JOSÉ
}

\begin{tabular}{|c|c|}
\hline \multicolumn{2}{|c|}{ ARTÍCULO INÉDITO DE INVESTIGACIÓN } \\
\hline CÓMO CITAR ESTE ARTÍCULO (CHICAGO) & $\begin{array}{l}\text { Bronstein, Arturo, "Erradicación del } \\
\text { trabajo forzoso: Perspectivas desde } \\
\text { Ginebra, Estrasburgo y San José". Revista } \\
\text { de Derecho Aplicado LLM UC } 4 \text { (2019). } \\
\text { doi: 10.7764/rda.o.4·4006 }\end{array}$ \\
\hline REVISTA DE DERECHO APLICADO LLM UC & $\begin{array}{l}\text { Número } 4 \\
\text { Diciembre } 2019 \\
\text { ISSN: } 245^{2-4344}\end{array}$ \\
\hline & $\begin{array}{l}\text { Recepción: I8 de noviembre, } 2019 \\
\text { Aceptación: I7 de diciembre, 20I9 }\end{array}$ \\
\hline
\end{tabular}




\section{Resumen}

Esta contribución ofrece un panorama de los diferentes dispositivos jurídicos que desde los tiempos de la (hoy extinta) Sociedad de las Naciones fueron formulados y desarrollados con miras a erradicar la esclavitud, primero, y el trabajo forzoso en sus diferentes formas desde 1930 en adelante. Con ese objeto, se comenzará mediante una breve aproximación a los instrumentos internacionales que han abordado el tema; a continuación, se hará una revisión de los sistemas de monitoreo y control de la aplicación de aquellos instrumentos. Por último, presentaremos algunos planteamientos concretos de la Comisión de Expertos en Aplicación de Convenios y Recomendaciones de la OIT, CEACR, tres sentencias del Tribunal Europeo de Derechos Humanos y un fallo de la Corte Interamericana de Derechos Humanos.

Palabras clave: Esclavitud, trabajo forzoso, Sociedad de las Naciones, Organización Internacional del Trabajo, Tribunal Europeo de Derechos Humanos, Corte Interamericana de Derechos Humanos.

\section{Abstract}

This contribution undertakes a review of the different legal devices that since the time of the (now extinct) League of Nations were formulated and developed with a view to eradicating slavery, first, and forced labor in its different forms from 1930 onwards. To this end, it will begin with a brief overview of the international instruments that have addressed the issue. Next, a review of the monitoring and control systems of the application of those instruments will be made. Finally, we will present some concrete approaches by the ILO Committee of Experts on the Application of Conventions and Recommendations, CEACR, three judgments by the European Court of Human Rights and a ruling by the Inter-American Court of Human Rights.

Keywords: Slavery, forced labour, League of Nations, International Labour Organization, European Court of Human Rights, Inter-American Court of Human Rights. 


\section{Arturo Bronstein}

Universidad Centro

Latinoamericano de

Economía Humana

Punta del Este, Uruguay

bronstein.arturo@gmail.com
Universidad Centro

Latinoamericano de

Economía Humana

Punta del Este, Uruguay

bronstein.arturo@gmail.com
Arturo Bronstein es abogado por la Universidad de Buenos Aires, Argentina. Trabajó en la Oficina Internacional del Trabajo (OIT) entre 1974 y 2005, como director adjunto del Departamento de Acción Gubernamental, Legislación y Administración del Trabajo en Ginebra (2000) y consejero principal de OIT en políticas de legislación del trabajo (2001), entre otros cargos. Ha sido profesor invitado en las universidades de París-X y York, Canadá; Sydney, Australia; y Monash, Australia, entre otras. Ha sido Secretario General de la Sociedad Internacional de Derecho del Trabajo y de la Seguridad Social (2001-2012), de la que actualmente es presidente honorario, y académico de número de la Academia Iberoamericana de Derecho del Trabajo y de la Seguridad Social. Es autor de numerosas obras jurídicas en derecho laboral, entre las que destacan Derecho internacional y comparado del trabajo: Desafíos actuales (Plaza y Valdés, 2010) y Derecho internacional del trabajo (Astrea, 2013).

Arturo Bronstein is a Lawyer from the University of Buenos Aires, Argentina. He worked at the International Labor Office (ILO) between 1974 and 2005, where he was Deputy Director of the Department of Government Action Labour Legislation and Labour Administration in Geneva (2000) and Senior Labour Law Policty Advisor (2001), among other positions. He has been a visiting professor at the universities of Paris-X and York, Canada; Sydney, Australia; and Monash, Australia, among others. He has been Secretary General of the International Society of Labour and Social Security Law (ISL\&SSL) of which he is currently a Honorary President $\mathrm{He}$ is the author of numerous legal works in Labor Law, among which International and Comparative Labour Law: Current Challenges (Red Globe Press, 2009) and Derecho internacional del trabajo (Astrea, 2013) stand out. 


\section{INSTRUMENTOS INTERNACIONALES}

Si bien la esclavitud es tan antigua como la organización social, fue recién con la Declaración de las Potencias para la Abolición del Comercio de Negros ${ }^{1}$, firmada el 8 de febrero de 1815 en el marco del Congreso de Viena, que se dieron los primeros pasos para coordinar los esfuerzos internacionales con el fin de terminar con la trata de esclavos.

Inmediatamente después del Congreso de Viena se adoptaron leyes nacionales y se concluyeron tratados bilaterales por los cuales se instituían la prohibición de la trata de esclavos y sanciones penales contra esa práctica. También se suscribieron acuerdos multilaterales con el mismo fin, en particular el Tratado de Londres del 20 de diciembre de 1841 sobre la abolición de la trata de esclavos; el Acta General de la Conferencia de Berlín del 26 de febrero de 1885, que prohibió la trata de esclavos en la cuenca del Congo; el Acta General de la Conferencia Antiesclavista, reunida en Bruselas del 18 de noviembre de 1889 al 2 de julio de 1890 para lograr la supresión de la trata de esclavos; el Acuerdo internacional del 18 de mayo de 1904; el Convenio internacional del 4 de mayo de 1910 para la represión de la trata de blancas, y el Convenio internacional de 1921 para la represión de la trata de mujeres y niños.

\section{I.I. Convención sobre la Esclavitud, I926 (Sociedad de las Naciones)}

En 1926, la Asamblea de la Sociedad de las Naciones adoptó la Convención sobre la Esclavitud $^{2}$, que es generalmente reconocida como el primer instrumento internacional de lo que hoy llamamos derecho internacional de los derechos humanos. En una amplia medida, la Asamblea y la convención que esta aprobó se basaron en los trabajos de una Comisión Temporal sobre la Esclavitud que había sido constituida en 1924 por mandato precisamente de la Sociedad de las Naciones.

Algunos comentarios merece esta Convención. El primero es que no se entendió como un instrumento global, sino que su mirada estuvo enfocada de preferencia en la situación de la "población nativa" de los territorios africanos, en aquella época con un estatus de colonia o dependencia de una potencia europea, o bajo mandato atribuido por la Sociedad de las Naciones a una de las potencias vencedoras de la Primera Guerra Mundial. Sin

1 "Declaración de las Potencias para la Abolición del Comercio de Negros", Dipublico,org, https://www.dipublico.org/I6277/declaracion-de-las-potencias-para-la-abolicion-del-comercio-de-negros-firmado-en-viena-el-8-de-febrero-de-I8I5/.

2 “Convención sobre Esclavitud”, Oficina del Alto Comisionado de Naciones Unidas sobre Derechos Humanos, https://www.ohchr.org/SP/ProfessionalInterest/Pages/SlaveryConvention. aspx. 
que llegara a excluirlas, la Convención no tuvo en cuenta a otras regiones del mundo, en especial América Latina, en donde, si bien la esclavitud había sido abolida en todos los países, subsistían no obstante diversas formas de trabajo forzoso.

El segundo comentario concierne a la definición de la esclavitud y la trata de esclavos por la Convención, que se formuló así:

1) La esclavitud es el estado o condición de un individuo sobre el cual se ejercitan los atributos del derecho de propiedad o algunos de ellos. 2) La trata de esclavos comprende todo acto de captura, adquisición o cesión de un individuo para venderle o cambiarle; todo acto de cesión por venta o cambio de un esclavo, adquirido para venderle o cambiarle, y en general todo acto de comercio o de transporte de esclavos.

Además de la esclavitud y la trata de esclavos, la Convención reconoció la existencia de ciertas formas de trabajo forzoso $u$ obligatorio diferentes de la esclavitud, reconocimiento que se refleja en la expresión "algunos atributos del derecho de propiedad". Sin embargo, no las definió ni tampoco las prohibió, aunque sí las limitó disponiendo en primer lugar que los Estados parte que tuvieran territorios no metropolitanos bajo su soberanía, jurisdicción, protección, dominio o tutela, deberían "tomar las medidas pertinentes para evitar que el trabajo forzoso u obligatorio lleve consigo condiciones análogas a la esclavitud”. Además, solo se podría exigir para "fines de pública utilidad" (artículo 5.1). De no ser así, el trabajo forzoso solo se debería emplear "a título excepcional, con una remuneración adecuada y a condición de que no pueda imponerse un cambio del lugar habitual de residencia" (artículo 5.2).

Como veremos enseguida, incumbió a la Organización Internacional del Trabajo (OIT) la tarea de definir lo que se entiende por "trabajo forzoso".

\section{I.2. Convenio sobre el Trabajo Forzoso, $193^{\circ}$ (OIT)}

Las labores de la Comisión Temporal sobre la Esclavitud habían revelado con claridad que la supresión de la esclavitud y la trata de esclavos no necesariamente pondrían fin a todas las prestaciones de trabajo de carácter servil que no encajaban en la definición de esclavitud, pero asumían no obstante algunos de sus elementos. Agregaremos que no faltaban pruebas de que el trabajo forzoso podía resultar y de hecho había resultado en males análogos a algunos de los producidos por la esclavitud. Esta preocupación fue reconocida por la Asamblea de la Sociedad de las Naciones, que en una resolución consecutiva a la adopción de la Convención sobre la Esclavitud, pidió al Consejo de la Sociedad de las Naciones que 
informe al Consejo de Administración de la Oficina Internacional del Trabajo sobre la adopción de la Convención sobre la Esclavitud, y llam(e)ar su atención sobre la importancia del trabajo realizado por la Oficina con miras a estudiar los mejores medios para prevenir que el uso del trabajo forzado $u$ obligatorio se convierta en condiciones análogas a esclavitud ${ }^{3}$.

A la luz de este mandato, la Oficina de la OIT elaboró un informe en $1929^{4}$, seguido de un cuestionario, a partir de los cuales se adoptó en 1930 el Convenio sobre el Trabajo Forzoso (núm. 29) ${ }^{5}$. Al 31 de octubre de 2019, este convenio ha sido ratificado por 178 de los 187 Estados miembros de la OIT $^{6}$.

Este convenio, siguiendo a la Convención sobre la Esclavitud de 1926, estuvo centrado en la protección de las poblaciones nativas de los territorios no metropolitanos. Sin embargo, al no haber formulado de manera explícita ninguna exclusión de otros colectivos de personas, se consideró que sería de aplicación general.

El Convenio 29 formula una definición de lo que se entiende por "trabajo forzoso" que va mucho más allá de la esclavitud a que se refiere la Convención de 1926. A ese efecto, considera como trabajo forzoso a "todo trabajo o servicio exigido a un individuo bajo la amenaza de una pena cualquiera y para el cual dicho individuo no se ofrece voluntariamente". No obstante, el Convenio establece algunas exenciones concretas para casos en los que de otro modo se hubiese aplicado la definición de trabajo forzoso u obligatorio. Entre otras, no prohíbe el trabajo penitenciario, pero establece restricciones para su utilización ${ }^{7}$. Tampoco considera como trabajo forzoso a los exigidos en virtud de leyes sobre el servicio militar

3 Jean Goudal, "The Question of Forced Labour before the International Labour Conference". International Labour Review ig, n. ${ }^{\circ} 5$ (I929).

4 "Forced Labour Report and Draft Questionnaire", Conferencia de la Organización Internacional del Trabajo, I929, https://www.ilo.org/public/libdoc/ilo/ıg2g/2gBog_io_engl.pdf.

5 “Convenio sobre el trabajo forzoso, I930 (núm. 29)", Organización Internacional del Trabajo, https://www.ilo.org/dyn/normlex/es/f?p=NORMLEXPUB:I2I00:0::NO::PI2I00 ILO CODE:Co2g.

6 Véase la base de datos Normlex de la OIT, recuperada de: https://www.ilo.org/dyn/normlex/ es/f?p=1000:I200I:.:NO.:.. Sin embargo, entre los países que aún no lo han ratificado figuran China y Estados Unidos, es decir, el país más poblado y la primera potencia económica del mundo, respectivamente.

$7 \quad$ En concreto, establece que el trabajo de los detenidos solo puede ser exigido en virtud de una sentencia judicial, se debe hacer bajo la vigilancia y control de las autoridades públicas y que dicho individuo no sea cedido o puesto a disposición de particulares, compañías o personas jurídicas de carácter privado. 
obligatorio y que tengan un carácter puramente militar, a aquellos trabajos o servicios que formen parte de las obligaciones cívicas normales de los ciudadanos o aquel que pudiera ser exigido en casos de fuerza mayor como guerra, siniestros, inundaciones, hambrunas, epidemias, epizootias u otras circunstancias que pongan en peligro o amenacen poner en peligro la vida o las condiciones normales de existencia de toda o parte de la población.

Vale la pena añadir que este convenio no contemplaba la abolición inmediata del trabajo forzoso, sino más bien su supresión progresiva, a cuyos efectos fijó un período transitorio durante el cual podría emplearse "únicamente para fines públicos y a título excepcional" (artículo 1). Es evidente que, a casi 90 años de su adopción, esta excepción ya ha caduca$\mathrm{do}^{8}$. Tampoco había incluido una definición de la trata o tráfico de personas con fines de explotación laboral o sexual; sin embargo, y sin duda bajo la influencia del Protocolo de Palermo al que nos referiremos más adelante, los órganos encargados del monitoreo de la aplicación de los convenios de la OIT la han asimilado al trabajo forzoso y exigen que los Estados que han ratificado el Convenio 29 tomen también medidas para prohibirla y reprimirla, incluso con sanciones penales ${ }^{9}$.

Además de su importancia intrínseca, este convenio, como todo convenio de la OIT, remite a un sofisticado procedimiento de monitoreo y control de su aplicación, que incluye la intervención de un órgano independiente (la Comisión de Expertos en Aplicación de Convenios y Recomendaciones, CEACR), el examen tripartito por la Conferencia Internacional del Trabajo y el depósito de reclamaciones y quejas no solo entre los Estados partes, sino también por sujetos de derecho privado como pueden ser las organizaciones de empleadores y de trabajadores ${ }^{10}$. Sobre esto volveremos más adelante.

\section{I.3. Instrumentos internacionales posteriores a $193^{\circ}$}

En primer lugar, corresponde que mencionemos a la Declaración Universal de los Derechos Humanos, adoptada por la Asamblea General de Naciones Unidas en 1948. Si bien no es un tratado vinculante, ofrece una base normativa y sobre todo ética y filosófica para otros instrumentos internacionales de derechos humanos. La Declaración consagra

8 Véase "Estudio general relativo al Convenio sobre el trabajo forzoso, I93o (núm. 29), y al Convenio sobre la abolición del trabajo forzoso, i957 (núm. I05)”, Conferencia Internacional del Trabajo, 96. ${ }^{a}$ reunión, 2007, párrafo Io, https://www.ilo.org/wcmsp5/groups/public/---ed_norm/---relconf/documents/meetingdocument/wcms_o8g20I.pdf.

$9 \quad$ En virtud del artículo 25 del Convenio, el hecho de imponer trabajo forzoso u obligatorio “será objeto de sanciones penales y las sanciones impuestas por la ley deberán ser realmente eficaces y aplicarse estrictamente".

10 “Mecanismo de control”, Organización Internacional del Trabajo, https://www.ilo.org/global/ about-the-ilo/how-the-ilo-works/ilo-supervisory-system-mechanism/lang--es/index.htm. 
la prohibición de la esclavitud y la servidumbre con arreglo a su artículo 4, que dispone: "Nadie estará sometido a esclavitud ni a servidumbre; la esclavitud y la trata de esclavos están prohibidas en todas sus formas"11.

En orden cronológico, vendría a continuación el Convenio para la Represión de la Trata de Personas y de la Explotación de la Prostitución Ajena, de 1949 ${ }^{12}$. Este instrumento consolida varios tratados preexistentes relativos a la prohibición de la esclavitud, la trata de mujeres y niños, y la prostitución forzosa.

Luego vendría un instrumento regional de gran importancia, el Convenio Europeo de Derechos Humanos de $1950^{13}$, que en su artículo 4 dispone: "Nadie podrá ser sometido a esclavitud o servidumbre" (artículo 4.1) y "nadie podrá ser constreñido a realizar un trabajo forzado u obligatorio" (artículo 4.2). El Convenio también enumera excepciones a la definición de "trabajo forzado u obligatorio", que en gran medida se corresponden con las que ya había enunciado el Convenio 29 de la OIT en 1930. En virtud de su Protocolo 11 de 1994, vigente desde el 1 de noviembre de 1998, se confirió competencia al Tribunal Europeo de Derechos Humanos para conocer de demandas presentadas "por cualquier persona física, organización no gubernamental o grupo de particulares que se considere víctima de una violación por una de las Altas Partes Contratantes de los derechos reconocidos en el Convenio o sus Protocolos".

La Convención Suplementaria sobre la Abolición de la Esclavitud, la Trata de Esclavos y las Instituciones y Prácticas Análogas a la Esclavitud ${ }^{14}$ fue adoptada en 1956 por una con-

11 La Declaración no es un tratado vinculante en derecho internacional (pues no está abierta a la ratificación por los Estados miembros de Naciones Unidas), pero sí puede serlo en el derecho interno de aquellos Estados que la han incorporado a su respectivo bloque de constitucionalidad. Por ejemplo, la Constitución española dispone en su artículo ro que "las normas relativas a los derechos fundamentales y a las libertades que la Constitución reconoce se interpretarán de conformidad con la Declaración Universal de Derechos Humanos y los tratados y acuerdos internacionales sobre las mismas materias ratificados por España”. Aún más explícita es la Constitución argentina, que junto con varios tratados de derechos fundamentales reconoce y confiere jerarquía constitucional a la Declaración Universal de los Derechos Humanos (artículo $75 \cdot 2)$.

12 "Convenio para la Represión de la Trata de Personas y de la Explotación de la Prostitución Ajena”, Oficina del Alto Comisionado de Naciones Unidas sobre Derechos Humanos, https:// www.ohchr.org/sp/professionalinterest/pages/trafficinpersons.aspx.

13 "Convenio Europeo de Derechos Humanos", Corte Europea de Derechos Humanos, https:// www.echr.coe.int/Documents/Convention_SPA.pdf.

14 "Convención suplementaria sobre la abolición de la esclavitud, la trata de esclavos y las instituciones y prácticas análogas a la esclavitud”, Oficina del Alto Comisionado de Naciones Unidas sobre Derechos Humanos, https://www.ohchr.org/SP/ProfessionalInterest/Pages/SupplementaryConventionAbolitionOfSlavery.aspx. A octubre de 20I9, cuenta con $12_{4}$ Estados partes. 
ferencia de plenipotenciarios convocada por el Consejo Económico y Social de Naciones Unidas. Su objeto fue prohibir ciertas prácticas de trabajo forzoso que no encajaban de manera estricta en la definición de esclavitud que ofrece la Convención de 1926, pero que de hecho obligaban a la prestación de un trabajo o servicio para el cual la persona no se había ofrecido en forma voluntaria, como ya en 1930 lo había contemplado el Convenio 29 de la OIT. Dentro de estas prácticas prohibidas se incluyen la servidumbre por deudas, la servidumbre de la gleba, el matrimonio forzoso o la entrega de niños o menores de dieciocho años por sus padres, o tutor, a otra persona con el propósito de su explotación.

El Convenio sobre la Abolición del Trabajo Forzoso (núm. 105) ${ }^{15}$, adoptado por la Conferencia Internacional del Trabajo en 1957, dispone la abolición de todas las formas de trabajo forzoso u obligatorio en cinco casos específicos que no habían sido claramente identificados en el Convenio 29, a saber: a) como instrumento de coerción o de educación políticas o como castigo por tener o expresar determinadas opiniones políticas o por manifestar oposición ideológica al orden político, social o económico establecido; b) como método de movilización y utilización de la mano de obra con fines de fomento económico; c) como medida de disciplina en el trabajo; d) como castigo por haber participado en huelgas; y e) como medida de discriminación racial, social, nacional o religiosa. Si se tiene en cuenta el año de la adopción de este convenio y el clima de Guerra Fría entonces existente, no es difícil colegir que al menos los apartados a) hasta c) antes citados tenían en mira muy especialmente a ciertas prácticas de trabajo forzoso propias de los gulaǵs soviéticos, mientras que el apartado e) respondía a las prácticas de trabajo esclavo del régimen de la Alemania nazi. Como dato anecdótico, diremos que este es el único convenio de la OIT en donde figura la palabra "huelga"16. Aun cuando no sea totalmente exacto, se pudiera decir que el Convenio 105 tiene como objeto prohibir la legislación y prácticas que buscan imponer trabajo forzoso como sanción o castigo, a diferencia del Convenio 29, que tenía en mira la prohibición del trabajo forzoso u obligatorio con fines de producción o servicio. El Pacto Internacional de Derechos Civiles y Políticos ${ }^{17}$, de 1966, dispone: "1) Nadie estará

15 “Convenio sobre la abolición del trabajo forzoso, I957 (núm. I०5)”, Organización Internacional del Trabajo, https:/www.ilo.org/dyn/normlex/es/f?p=I000:I2100:0::NO::PI2I00_ILO_CO-

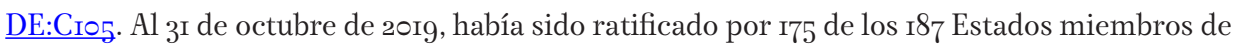
la OIT. Entre los países que no lo han ratificado se encuentra China.

16 Artículo r, letra d): "Se prohíbe el trabajo forzoso [...] d) como castigo por haber participado en huelgas".

17 "Pacto Internacional de Derechos Civiles y Políticos", Oficina del Alto Comisionado de Naciones Unidas sobre Derechos Humanos, https://www.ohchr.org/SP/ProfessionalInterest/Pages/ CCPR.aspx. Este instrumento internacional ha recibido 173 ratificaciones o adhesiones al $3^{\mathrm{I}} \mathrm{de}$ octubre de 20I9. Entre los países que no lo han ratificado figuran Cuba y la República Popular China, aunque esta última lo ha declarado aplicable a la Zona Administrativa Especial de Hong Kong. 
sometido a esclavitud. La esclavitud y la trata de esclavos estarán prohibidas en todas sus formas" y “2) Nadie estará sometido a servidumbre”. A semejanza de otros instrumentos internacionales, el Pacto enuncia varias excepciones que en una medida muy amplia retoman las ya previstas en el Convenio 29 de la OIT.

En virtud de un protocolo facultativo ${ }^{18}$ (entrado en vigor en 1976) se confirió al Comité de Derechos Humanos (instituido en virtud del artículo 28 del Pacto) la facultad de recibir "comunicaciones" (léase quejas) de "todo individuo que alegue una violación de cualquiera de sus derechos enumerados en el Pacto y que haya agotado todos los recursos internos disponibles".

La Convención Americana sobre Derechos Humanos ${ }^{19}$ de 1969 (también llamada Pacto de San José) en vigencia desde julio de 1978, dispone en su artículo 6: "Nadie puede ser sometido a esclavitud o servidumbre, y tanto estas, como la trata de esclavos y la trata de mujeres están prohibidas en todas sus formas". Las excepciones son muy similares a las que contempla el Pacto Internacional de Derechos Civiles y Políticos, a su vez inspiradas en el Convenio 29 de la OIT. La Convención contiene disposiciones sobre su seguimiento y aplicación por la Comisión Americana de Derechos Humanos, que eventualmente puede someter casos ante la Corte Interamericana de Derechos Humanos. Este procedimiento está abierto a "cualquier persona o grupo de personas, o entidad no gubernamental legalmente reconocida en uno o más Estados miembros de la Organización [de Estados Americanos (OEA), quienes pueden] presentar a la Comisión peticiones que contengan denuncias o quejas de violación de esta Convención por un Estado parte". También aquí se exige que con carácter previo se hayan agotado los recursos jurisdiccionales en el Estado contra el que se dirige la petición (queja o querella en la práctica), pero esto puede ser obviado en caso de demora injustificada de trámite por el Gobierno, o demora de la decisión del correspondiente órgano judicial del Estado contra el que se dirige la petición. El Protocolo de las Naciones Unidas para Prevenir, Reprimir y Sancionar la Trata de

18 "Protocolo Facultativo del Pacto Internacional de Derechos Civiles y Políticos", Oficina del Alto Comisionado de Naciones Unidas sobre Derechos Humanos, https://www.ohchr.org/SP/ProfessionalInterest/Pages/OPCCPRI.aspx. El Protocolo ha sido ratificado o declarado vinculante por accesión por in6 Estados. Entre los países que no lo han suscrito figura Estados Unidos.

19 “Convención Americana sobre Derechos Humanos (Pacto de San José)”, Organización de Estados Americanos, https://www.oas.org/dil/esp/tratados_b-32_convencion_americana_sobre_ derechos_humanos.htm. La Convención ha sido ratificada por 26 de los Estados miembros de la OEA y denunciada por uno de ellos: la República Bolivariana de Venezuela denuncia que fue dejada sin efecto por la Asamblea Legislativa en 20I9. Estados Unidos es uno de los miembros que no la ratificó. 
Personas, Especialmente Mujeres y Niños (Protocolo sobre la Trata) ${ }^{20}$, conocido como Protocolo de Palermo, adoptado en el año 2000, en vigor desde el 25 de diciembre de 2003, es un protocolo de la Convención de Naciones Unidas contra la Delincuencia Organizada Transnacional ${ }^{21}$. Persigue tres finalidades: "a) Prevenir y combatir la trata de personas, prestando especial atención a las mujeres y los niños; b) proteger y ayudar a las víctimas de dicha trata, respetando plenamente sus derechos humanos; y c) promover la cooperación entre los Estados partes para lograr esos fines”.

El Convenio contra la Trata de Seres Humanos del Consejo de Europa ${ }^{22}$, de 2005, vigente desde 2008, se inspiró en el Protocolo de Palermo. Tiene la particularidad de que está abierto a la accesión por Estados que no son miembros del Consejo de Europa. Su objeto es prevenir la trata de seres humanos, proteger a las víctimas de la trata, encausar a los traficantes y promover la coordinación de la acción nacional y la cooperación internacional. El Convenio se aplica a todas las formas de trata, ya sean nacionales o transnacionales, vinculadas o no con el crimen organizado, a todas las víctimas de la trata (mujeres, hombres y niños), y a todas las formas de explotación (sexual, trabajo o servicios forzados, esclavitud, servidumbre y extirpación de órganos, etcétera).

El Protocolo de 2014 relativo al Convenio sobre el Trabajo Forzoso (OIT) de $1930^{23}$ fue adoptado por la Conferencia Internacional del Trabajo en junio de 2014 y entró en vigor en noviembre de 2016. Dispone que los Estados que lo han ratificado deben adoptar medidas relativas a la prevención, protección y acciones jurídicas y de reparación para dar efecto a

20 "Protocolo para prevenir, reprimir y sancionar la trata de personas, especialmente mujeres y niños, que complementa la Convención de las Naciones Unidas contra la Delincuencia Organizada Transnacional”, Oficina del Alto Comisionado de Naciones Unidas sobre Derechos Humanos, https://www.ohchr.org/Documents/ProfessionalInterest/ProtocolTraffickingInPersons_sp.pdf. $\mathrm{Al}_{3} \mathrm{I}$ de octubre de 20I9, I75 Estados han ratificado o adherido a este Protocolo.

21 Del I5 de noviembre de 2000 , en vigor desde el 29 de septiembre 2003. A la fecha, I9o Estados partes han firmado.

22 “Convention du Conseil del'Europe sur la lutte contre la traite des êtres humains”, Consejo Europeo, https:/www.coe.int/en/web/conventions/full-list/-/conventions/rms/og0000I68008373I. $\mathrm{Al}_{3}$ I de octubre de 2org, había sido ratificado por todos los Estados miembros del Consejo de Europa —excepto Rusia-y por un no miembro, Bielorrusia.

23 "Protocolo de 20I 4 relativo al Convenio sobre el trabajo forzoso, I930", Organización Internacional del Trabajo, https:/www.ilo.org/dyn/normlex/es/f?p=NORMLEXPUB:I2I00:0::NO::Pi2ioo_ILO_CODE:Po2g. Al 3 I de octubre de 20I9, ya había sido ratificado por 53 Estados miembros de la OIT. 
la obligación de suprimir el trabajo forzoso establecida por el Convenio 29. Lo complementa la Recomendación sobre el Trabajo Forzoso (Medidas Complementarias), 2014 (núm. 203 ${ }^{24}$, adoptada por la Conferencia de la OIT junto con el anterior protocolo. Como toda recomendación de la OIT, su contenido no es vinculante, pero ofrece lineamientos muy útiles acerca de las medidas que se podrían adoptar con miras a dar efectos al Protocolo.

Para concluir esta sección, haremos una breve mención a otros instrumentos internacionales que incluyen aunque sea de manea tangencial este tema, como el Pacto Internacional de Derechos Económicos, Sociales y Culturales ${ }^{25}, 1966$ (artículo 6, inciso primero), el Convenio de la OIT sobre pueblos indígenas y tribales de 1989 (núm. 169) ${ }^{26}$ (artículos 11 y 20.3 letra c), el Estatuto de Roma de la Corte Penal Internacional de 1998 (artículo 7); el Convenio de la OIT sobre las Peores formas de trabajo infantil de 1999 (núm. 182) ${ }^{28}$ (artículo 3); y la Carta Africana de Derechos Humanos y de los Pueblos de $1981^{29}$ (artículo 5), entre otros.

\section{FORMAS CONTEMPORÁNEAS DE ESCLAVITUD}

A pesar de que la esclavitud tradicional ha sido abolida en todos los países del mundo, todavía quedan resabios en algunos de ellos, como lo destacan numerosos documentos

24 “Recomendación sobre el trabajo forzoso (medidas complementarias), 20I4 (núm. 203)", Organización Internacional del Trabajo, https://www.ilo.org/dyn/normlex/es/f?p=NORMLEXPUB:I2100:0::NO:I2100:PI2100_INSTRUMENT_ID:317,688:NO.

25 "Pacto Internacional de Derechos Económicos, Sociales y Culturales", Oficina del Alto Comisionado de Naciones Unidas sobre Derechos Humanos, https://www.ohchr.org/Documents/ ProfessionalInterest/cescr_SP.pdf.

26 “Convenio sobre pueblos indígenas y tribales, I989 (núm. I69)”, Organización Internacional del Trabajo, https:/www.ilo.org/dyn/normlex/es/f?p=NORMLEXPUB:I2I00:0::NO:I2100:PI2I00_ INSTRUMENT_ID:3I23I:N:NO.

27 “Estatuto de Roma de la Corte Penal Internacional”, Naciones Unidas, A/Conf. I83/9, I7 de julio de I998, https://www.oas.org/xxxivga/spanish/reference_docs/Estatuto_Roma.pdf.

28 "Convenio sobre las peores formas de trabajo infantil, i999 (núm. I82)", Organización Internacional del Trabajo, https:/www.ilo.org/dyn/normlex/es/f?p=NORMLEXPUB:I2I00:0::NO::PI2100_ILO_CODE:CI82.

29 "Carta Africana de Derechos Humanos y de los Pueblos", Oficina del Alto Comisionado de Naciones Unidas sobre Derechos Humanos, https://www.acnur.org/fileadmin/Documentos/ BDL/2002/1297.pdf. 
de la $\mathrm{OIT}^{30}$, sin hablar de los aún más numerosos de reconocidas ONG que abogan por el respeto de los derechos humanos fundamentales. En efecto, si bien el ejercicio del derecho de propiedad sobre otras persona al que se refiere la Convención de 1926 ya es ilegal en todos los países del mundo, aún existen muchos casos en los que es flagrante el ejercicio de algunos de los atributos de aquel derecho, de modo que en la actualidad muchos millones de personas de jure o de hecho, y bajo amenazas o coacción, son obligadas a ejecutar trabajos o prestar servicios para los cuales no se han ofrecido de forma voluntaria.

Lejos de ser un fenómeno marginal, se estima que en 2016 alrededor de 40,3 millones de personas fueron víctimas de esclavitud moderna. En otras palabras, en un día cualquiera de aquel año es probable que más de 40 millones de hombres, mujeres y niños hayan sido obligados a trabajar contra su voluntad bajo amenazas, o a vivir en un matrimonio forzoso al que no habían prestado su consentimiento. De estos millones de víctimas, 24,9 millones se encontraban en situación de trabajo forzoso. Esto equivale a decir que estaban obligadas a trabajar, bajo amenazas o coacción, como trabajadores domésticos, como obreros en el sector de la construcción, en fábricas clandestinas, en explotaciones agrícolas y en buques pesqueros, en la industria sexual y en otros sectores. Dicho trabajo obligatorio se efectuaba en beneficio de personas o grupos del sector privado, o bien de autoridades estatales. En muchos casos, los productos que fabricaban o los servicios que prestaban formaban parte de circuitos comerciales en apariencia legítimos. Dicho de una manera más directa y cercana, las personas sometidas a trabajo forzoso producen parte de los alimentos que consumimos y de la ropa que usamos, y han limpiado los edificios en los que muchos vivimos o trabajamos ${ }^{31}$.

Lejos de estar en retroceso, algunas de estas prácticas han recrudecido. En contrario a lo que se pudiera creer, no están restringidas a un puñado de países en vías de desarrollo de Asia, África o América Latina, sino que bajo una o más de las siguientes formas existen en casi todos, si no todos los países del mundo ${ }^{32}$ :

30 Por ejemplo, véase las observaciones reiteradas a Mauritania formuladas por la Comisión de Expertos en Aplicación de Convenios y Recomendaciones de OIT (https:/www.ilo.org/ dyn/normlex/es/f?p=I000:Iz100:0::NO:Iz100:PIzI00_COMMENT_ID:3499468) y su discusión por la Conferencia Internacional del Trabajo en 2017 (https:/www.ilo.org/dyn/normlex/es/ f?p=I000:I3100:0::NO:I3100:PI3100 COMMENT ID:3330956).

31 OIT y Walk Free Foundation, Estimaciones mundiales sobre la esclavitud moderna: Trabajo forzoso y matrimonio forzoso (Ginebra: Alliance 8.7, 20I7).

32 Conferencia Internacional del Trabajo, "Alto al trabajo forzoso: Informe global con arreglo al seguimiento de la Declaración de la OIT relativa a los principios y derechos fundamentales en el trabajo", Organización Internacional del Trabajo, 200I, https:/www.ilo.org/wcmsp5/groups/ public/---dgreports/---dcomm/---publ/documents/publication/wcms_publ_9223II9480_ es.pdf. Véase también: Conferencia Internacional del Trabajo, "El costo de la coacción”, Organización Internacional del Trabajo, https:/www.ilo.org/wcmsp5/groups/public/---ed_norm/---declaration/documents/publication/wcms_io626g.pdf. 
- La esclavitud y el secuestro.

- Participación obligatoria en proyectos de obras públicas.

- Trabajo forzoso en la agricultura y en zonas rurales remotas.

- Trabajadores domésticos en situaciones de trabajo forzoso.

- Servidumbre por deudas.

- Trabajo forzoso impuesto por los militares.

- Trata de personas con fines de explotación laboral.

- Trata de personas con fines de explotación sexual.

- Algunos aspectos del trabajo en establecimientos penitenciarios en beneficio de personas privadas.

\section{I. Trata de personas con fines de explotación sexual o laboral}

En los últimos años, los esfuerzos nacionales e internacionales para erradicar el trabajo forzoso han estado enfocados preferentemente en la trata o tráfico de personas, cuestión que ha sido objeto del antes citado Protocolo de Palermo. El concepto de trata estuvo originariamente vinculado al tráfico de esclavos y en un segundo momento a la llamada "trata de blancas", definida como la captación de mujeres con fines de prostitución, En 1904 fue adoptado un acuerdo internacional para la represión de la trata de blancas al que sucedieron otros en 1910, 1921 y 1933, respectivamente. En el artículo 1 de este último se estableció la obligación de prohibir, evitar y castigar la trata de mujeres, incluso con su consentimiento. En 1949 la Asamblea General de Naciones Unidas adoptó el Convenio para la Represión de la Trata de Personas y de la Explotación de la Prostitución Ajena ${ }^{33}$, que unificó los instrumentos anteriores al definir como delito el hecho de que una persona concierte la prostitución de otra, incluso con su consentimiento. Sin embargo, la realidad actual muestra que no solo sigue existiendo la trata de mujeres con fines de prostitución, sino que además está muy difundida la trata con fines de explotación comercial o industrial. En el primer informe global sobre el trabajo forzoso de 2001, con arreglo al seguimiento de la Declaración de la OIT relativa a los principios y derechos fundamentales en el trabajo, se calificó la trata de seres humanos como "la otra cara de la mundialización". Desde entonces ha revestido nuevas formas y dimensiones, relacionadas con la evolución reciente de la tecnología, el transporte y la delincuencia organizada transnacional ${ }^{34}$.

La trata ha sido definida en el Protocolo de Palermo en los siguientes términos:

[Por] trata de personas se entiende la captación, el transporte, el traslado, la acogida o la recepción de personas, recurriendo a la amenaza o al uso de la fuerza

33 "Convenio para la represión de la trata de personas y de la explotación de la prostitución ajena", Oficina del Alto Comisionado de Naciones Unidas sobre Derechos Humanos, https:// www.ohchr.org/sp/professionalinterest/pages/trafficinpersons.aspx.

34 "Alto al trabajo forzoso", párrafo 4. 
u otras formas de coacción, al rapto, al fraude, al engaño, al abuso de poder o de una situación de vulnerabilidad o a la concesión o recepción de pagos o beneficios para obtener el consentimiento de una persona que tenga autoridad sobre otra, con fines de explotación. Esa explotación incluirá, como mínimo, la explotación de la prostitución ajena u otras formas de explotación sexual, los trabajos o servicios forzados, la esclavitud o las prácticas análogas a la esclavitud, la servidumbre o la extracción de órganos.

Por consiguiente, tres elementos deben estar presentes para que se configure el delito de trata o tráfico de seres humanos, a saber: i) la captación, el transporte, el traslado, la acogida o la recepción de personas; ii) el recurso a la amenaza o al uso de la fuerza u otras formas de coacción, al rapto, al fraude, al engaño, al abuso de poder o de una situación de vulnerabilidad; $\mathrm{y}$ iii) la finalidad de explotar a la víctima.

Esta definición es la que ha sido corrientemente adoptada por otros instrumentos internacionales que abordan el tema de la trata o el trabajo forzoso. Entre otras, la OIT es de opinión que se encuentra incluida dentro de su definición de trabajo forzoso. En consecuencia, considera que las medidas para combatir el trabajo forzoso deben incluir disposiciones y acciones efectivas para prevenir y reprimir la trata, incluyendo sanciones penales ${ }^{35}$.

\section{PERSPECTIVAS DESDE GINEBRA: LABOR DE LA OIT}

De todas las organizaciones internacionales, la OIT es la que ha acumulado más experiencia en la lucha contra el trabajo forzoso. A partir de los convenios sobre el trabajo forzoso, 1930 (núm. 29) (y ahora también su Protocolo de 2014) y sobre la abolición del trabajo forzoso, 1957 (núm. 105), la OIT se ha servido de su ejemplar sistema de control de la aplicación de sus normas como una herramienta para fustigar a los Gobiernos de los Estados miembros que no honran su obligación de dar cumplimiento a los convenios que han ratificado ${ }^{36}$. Este sistema reposa en dos pilares: el primero es el control regular, que se basa en la obligación que tienen todos los Estados miembros de someter memorias anuales $^{37}$, en las que deben informar sobre las medidas que han tomado para dar efecto

35 "Estudio general relativo al Convenio sobre el trabajo forzoso", párrafo 75 y ss.

36 Para una presentación detallada del sistema de control normativo de la OIT, véase "Manual sobre procedimientos en materia de convenios y recomendaciones internacionales del trabajo", Organización Internacional del Trabajo, 20I2, https://www.ilo.org/wcmsp5/groups/public/--ed_norm/---normes/documents/publication/wcms_ig2622.pdf.

37 En la práctica se presentan memorias cada dos años con relación a los ocho convenios fundamentales de OIT, entre los que figuran los Convenios 29 y I05, los cuatro convenios de gobernanza; y, cada cinco años, con respecto a los otros convenios ratificados. Las información sobre la aplicación de los convenios de OIT es subida a la base de datos NORMLEX, en https://www. ilo.org/dyn/normlex/es/f?p=NORMLEXPUB:I:o::NO:.:. 
a los convenios que han ratificado (artículo 22 de la Constitución de la OIT). Estas memorias, junto con cualquier información confiable ofrecida por otras fuentes, inclusive sindicatos, organizaciones de empleadores, ONG enfocadas en la defensa y protección de los derechos humanos fundamentales, y muy en especial los informes y relatorías del Alto Comisionado de las Naciones Unidas para los Derechos Humanos (ACNUD), son examinadas por la Comisión de Expertos en Aplicación de Convenios y Recomendaciones (CEACR), un cuerpo colegiado integrado por miembros independientes designados por el Consejo de Administración de la OIT. La CEACR puede formular solicitudes directas y observaciones individuales al Gobierno de algún miembro en particular; las observaciones por lo general tienen como objeto destacar los aspectos de la legislación o práctica nacional que a juicio de la CEACR reflejan inconsistencias con algún convenio ratificado o evidencian falta de celo para darle cumplimiento. Además, incluyen un llamamiento para que el miembro tome medidas idóneas para ponerse en regla. Al propio tiempo, la CEACR puede saludar evoluciones e iniciativas de los miembros que han tomado medidas para dar un cumplimiento más eficaz a los convenios que han ratificado, lo que en el lenguaje de la CEACR son llamados "casos de progreso" ${ }^{38}$. Observemos, no obstante, que si bien es cierto que al hacer su tarea la CEACR efectúa una labor de interpretación de los convenios de la OIT, esta no es jurídicamente vinculante, pues a tenor de lo dispuesto por la Constitución de la OIT (artículo 37), solo la Corte Internacional de Justicia tiene facultades para ofrecer una interpretación auténtica de la Constitución de la OIT y de las normas que adopta. Resta que las opiniones de la CEACR gozan de gran prestigio y autoridad, y no es para nada infrecuente que los tribunales nacionales se basen en ellas en oportunidad de interpretar y aplicar la legislación doméstica.

El informe anual de la CEACR es elevado a la Comisión de Aplicación de Normas de la Conferencia Internacional del Trabajo, de composición tripartita, que selecciona cierto número de casos relativos a las observaciones - alrededor de veinte por reunión de la Conferencia - para una discusión - a veces áspera - en la que el Gobierno del país concernido es invitado a dar explicaciones sobre los motivos por los que a juicio de la CEACR no ha dado cumplimiento al convenio en cuestión y las medidas que cuenta tomar para hacerlo. El informe de los trabajos de esta Comisión se hace público y a falta de tener efecto vinculante, se lo considera como una forma de sanción moral que es vista internacionalmente como una mancha que afecta la reputación moral del Estado en cuestión. En otras palabras, el procedimiento de monitoreo y control por la OIT tiende por así decirlo a "avergonzar" al Estado incumplidor con el objeto de que se sienta urgido para tomar alguna o diversas medidas para ponerse en regla con los convenios que han ratificado.

38 Véase por ejemplo la solicitud directa de la CEACR en 2018 al Gobierno de Chile por la aplicación del convenio sobre el trabajo forzoso, I930, https://www.ilo.org/dyn/normlex/es/ f?p=I000:IzI00:0::NO:IzI00:Pizi00_COMMENT_ID:3780,67. 
El segundo pilar del sistema de seguimiento y monitoreo por la OIT está constituido por los llamados "procedimientos especiales", que son el de reclamaciones, basado en el artículo 24 de la Constitución de la OIT, y el de quejas, basado en el artículo $26^{39}$. El primero puede ser iniciado por cualquier organización de empleadores o de trabajadores contra un Estado que a criterio del denunciante ha incumplido sus obligaciones dimanantes de un convenio que ha ratificado ${ }^{40}$. Por su parte, el segundo está abierto a todo delegado a la Conferencia Internacional del Trabajo, o a cualquier Estado contra otro Estado, siempre que los dos hayan ratificado el mismo convenio cuyo incumplimiento se alega. Un rasgo muy importante de estos procedimientos consiste en que, a diferencia de la inmensa mayoría de los procedimientos de quejas o reclamaciones en el ámbito internacional, aquí no se exige que se hayan agotado los recursos en el ámbito doméstico para que una denuncia y el subsiguiente procedimiento sean considerados admisibles. En realidad, tampoco es necesario que el procedimiento doméstico haya sido siquiera abierto. Estos procedimientos por lo general finalizan con la adopción de conclusiones acerca del cumplimiento o incumplimiento del convenio por el Estado incriminado, junto con recomendaciones acerca de las medidas que pudiera tomar para darle efecto. De nuevo, su objeto es avergonzar al Estado incumplidor para que tome las medidas que se le reclaman para dar cumplimiento a los convenios que ha ratificado. Esto puede ser de gran autoridad moral, aun cuando no sea jurídicamente vinculante.

Por otro lado, un tercer procedimiento es el de la Comisión de Encuesta. Se trata de un procedimiento muy solemne, que por lo general se abre cuando se presume que existen muy serias y reiteradas violaciones de un convenio ratificado, y estas son imputadas a la acción o la inacción del respectivo Gobierno. Desde que se fundó la OIT, en 1919, hasta el presente solo se han constituido 13 Comisiones de Encuesta, de las cuales las concernientes a República Dominicana y Haití, Liberia, Myanmar y Portugal fueron constituidas en seguimiento a quejas en las que se alegó el incumplimiento de los Convenios 29 y 105, o solamente uno de ellos.

Se incluye a continuación un listado - por cierto incompleto-de algunos casos notables que dieron lugar a observaciones de la CEACR. Todos han sido publicados en la base de datos Normlex ${ }^{41}$ y se pueden consultar en su sección "Perfiles por país".

39 Aparte de estos procedimientos, es indispensable mencionar el del Comité de Libertad Sindical. Véase "Manual sobre procedimientos", 50-52.

40 Interesa destacar que este procedimiento fue instituido por la Constitución de la OIT en I9I9 (entonces Parte i3 del Tratado de Versalles) y muy probablemente es el primer instrumento internacional en virtud del cual una disposición de derecho internacional puede ser invocada por una persona (jurídica) de derecho privado contra un Estado, pues hasta entonces las normas de derecho internacional solamente podían ser invocadas en las relaciones entre Estados.

41 Sitio web de Normlex, recuperado de https://www.ilo.org/dyn/normlex/es/f?p=NORMLEXPUB:I:O::NO::. 
- Persistencia de la esclavitud tradicional (Mauritania) ${ }^{42}$.

- Esclavitud de facto y prácticas análogas a la esclavitud (Brasili3, Níger $\left.{ }^{44}\right)$.

- Trata de personas con fines de explotación sexual o laboral (muchos países) ${ }^{45}$.

- Servidumbre por deudas (India ${ }^{46}$, Pakistan $^{47}, \mathrm{Nepal}^{48}$ ).

- Servidumbre doméstica (Haitít ${ }^{29}$, Kuwait $^{50}$, Bahrein $^{51}$ ).

- Leyes de vagancia (República Centroafricana ${ }^{52}$, Guinea) y de personas indigentes (Singapur ${ }^{53}$ ).

42 Observación individual de la CEACR, 2017 y conclusiones de la discusión por la Comisión de Aplicación de Normas de la Conferencia, https://www.ilo.org/dyn/normlex/es/ f?p=I000:I3100:0::NO:IzI00:PIzI00_COMMENT_ID:3499468:NO.

43 Observación individual de la CEACR, 20I5, https://www.ilo.org/dyn/normlex/es/ f?p=I000:I3100:0::NO:IzI00:PI3I00_COMMENT_ID:32528,6:NO.

44 Observación individual de la CEACR, 20I6, https://www.ilo.org/dyn/normlex/es/ f?p=I000:IzI00:0::NO:IzI00:PIzI00_COMMENT_ID:3287330. Véase también el informe de misión a Níger de la Relatora Especial de las Naciones Unidas sobre formas modernas de esclavitud incluidas sus causas y consecuencia, Asamblea General de la ONU, 20I5, https:// www.refworld.org/cgi-bin/texis/vtx/rwmain/opendocpdf.pdf?reldoc $=y \& d o c i d=5 f_{7} \mathrm{~d}_{4} 274$.

45 Conferencia Internacional del Trabajo, ro8. ${ }^{a}$ reunión, 20rg. Informe de la Comisión de Expertos en Aplicación de Convenios y Recomendaciones, https://www.ilo.org/wcmsp5/ groups/public/---ed_norm/---relconf/documents/meetingdocument/wcms_670I48.pdf. En este informe se han publicado numerosas observaciones, de las que se desprende que en casi todos los países se han adoptado leyes contra la trata de personas. Las preguntas de la CEACR hacen no obstante hincapié en la aplicación de estas leyes, cuya eficacia en la práctica tiende a dejar mucho que desear.

46 Observación individual de la CEACR, 2018, https://www.ilo.org/dyn/normlex/es/ f?p=I000:I3100:0::NO:IzI00:PIzI00_COMMENT_ID:3958308:NO.

Observación individual de la CEACR, 2017, https://www.ilo.org/dyn/normlex/es/ f?p=I000:I3100:0::NO:I3100:Prz100_COMMENT_ID:3327274.

48 Observación individual de la CEACR, 20I8, https://www.ilo.org/dyn/normlex/es/ f?p=I000:IzI00:0::NO:I3100:PIzI00_COMMENT_ID:3957894.

Observación individual de la CEACR, 2007, https:/www.ilo.org/dyn/normlex/es/ f?p=I000:I3100:0::NO:Iz100:PI3100_COMMENT_ID:2308782.

50 Observación individual de la CEACR, 20I5, https://www.ilo.org/dyn/normlex/es/ f?p=I000:I3100:0::NO:IzI00:PI3I00_COMMENT_ID:3254866.

51 Observación individual de la CEACR, 20I7, https://www.ilo.org/dyn/normlex/es/ f?p=I000:IzI00:0::NO:IzI00:PIzI00 COMMENT ID:33352I8.

52 Solicitud directa de la CEACR, 20I7, https://www.ilo.org/dyn/normlex/es/f?p=I000:I3100:0::NO::PIzI00 COMMENT ID,PIzI00 LANG CODE:33375I6,fr:NO.

53 Solicitud directa de la CEACR, 20I8, https://www.ilo.org/dyn/normlex/es/f?p=I000:I3I00:0::NO:Izioo:Pizioo COMMENT ID:329702g:NO. 
- Condiciones de trabajo forzoso en talleres textiles clandestinos con complicidad e inclusive implicación de funcionarios policiales en estas prácticas (Argentina) $)^{54}$.

- Penas de prisión que pueden conllevar trabajo forzoso por delito de opinión (Botsuana $^{55}$, Burundi ${ }^{56}$, Camboya, Camerún ${ }^{57}$ Egipto $^{58}$, Eritrea, Indonesia ${ }^{59}$, Libia, República Centroafricana, Kenia).

- Penas de prisión que pueden conllevar trabajo forzoso por incitar o participar en huelgas ilegales (Estado Plurinacional de Bolivia ${ }^{60}$, Marruecos ${ }^{61}$, Chile ${ }^{62}$ ).

- Penas de prisión que pueden conllevar trabajo forzoso por negativa a cumplir servicio civil (Argelia ${ }^{63}$ ).

- Penas de prisión que pueden conllevar trabajo forzoso por negativa a efectuar trabajos de interés general (Camerún $\left.{ }^{64}\right)$.

54 Observación individual de la CEACR, 20I8, https://www.ilo.org/dyn/normlex/es/

f?p=I000:IzI00:0::NO:IzI00:PIzI00_COMMENT_ID:3961030.

55 Observación individual de la CEACR, 20I8, https://www.ilo.org/dyn/normlex/es/

f?p=I000:IzI00:0::NO:IzI00:Pizi00_COMMENT_ID:3965712

56 Observación individual de la CEACR, 20I8, https://www.ilo.org/dyn/normlex/es/

f?p=I000:IzI00:0::NO:Iz100:PIzI00_COMMENT_ID:3953687.

57 Observación individual de la CEACR, 20I8, https://www.ilo.org/dyn/normlex/es/

f?p=I000:I3100:0::NO:I3100:PIzI00_COMMENT_ID:3336328.

58 Observación individual de la CEACR, 20I8, https://www.ilo.org/dyn/normlex/es/ f?p=I000:I3I00:0::NO:IzI00:PI3I00_COMMENT_ID:3957082.

59 Observación individual de la CEACR, 20I8, https://www.ilo.org/dyn/normlex/es/ f?p=I000:I3100:0::NO:IzI00:PI3I00_COMMENT_ID:3956472.

60 Observación individual de la CEACR, 2014, https://www.ilo.org/dyn/normlex/es/ f?p=I000:I3100:0::NO:I2100:PI3I00_COMMENT_ID:3I8g982.

61 Observación individual de la CEACR, 20I8, https://www.ilo.org/dyn/normlex/es/ f?p=I000:I3100:0::NO:I3100:Piz100_COMMENT_ID:395660I.

62 Solicitud directa de la CEACR, 20II, https://www.ilo.org/dyn/normlex/es/f?p=I000:I3I00:0::NO:Izioo:Pizioo_COMMENT_ID:269g2z2.

63 Observación individual de la CEACR, 2018, https://www.ilo.org/dyn/normlex/es/ f?p=I000:I3100:0::NO:I3100:PI3100_COMMENT_ID:3780/14.

64 Observación individual de la CEACR, 2007, https://www.ilo.org/dyn/normlex/es/ f?p=I000:IzI00:0::NO:IzI00:PIzI00_COMMENT_ID:2283833. 
- Trabajo de detenidos en prisiones privadas o en talleres privados dentro de establecimientos públicos de detención (Australia ${ }^{65}$, Austria ${ }^{66}$, Reino Unido ${ }^{67}$ ).

- Trabajos de interés público o con fines de desarrollo económico bajo amenaza de pena de prisión (Birmania ${ }^{68}$ ).

- Explotación sexual de niñas de castas inferiores (práctica llamada devadasi) $\left(\right.$ India $\left.{ }^{69}\right)$.

- Trabajo forzoso en comunidades indígenas $\left(\right.$ Paraguay $\left.^{70}\right)$.

- Trabajo forzoso infantil (muchos países).

- Tráfico de niños para su explotación como jinetes de camellos (Kuwait, Omán, Catar $\left.^{71}\right)$.

- Obligación de trabajar horas suplementarias sin remuneración (Guatemala ${ }^{72}$ ).

- Restricciones a la renuncia al empleo (Bangladesh ${ }^{73}$, Pakistán).

- Retorno forzoso de marineros a los buques mercantes de los que han desertado (Bahamas ${ }^{74}$, Jamaica, Papúa Nueva Guinea, Tailandia, Trinidad y Tobago).

65 Observación individual de la CEACR, 20I8, https://www.ilo.org/dyn/normlex/es/ f?p=I000:I3I00:0::NO:IzI00:PI3I00_COMMENT_ID:3780323.

66 Observación individual de la CEACR, 2017, https://www.ilo.org/dyn/normlex/es/ f?p=I000:IzI00:0::NO:IzI00:Pizio0_COMMENT_ID:334035I.

67 Observación individual de la CEACR, $20 \mathrm{I} 7$, https://www.ilo.org/dyn/normlex/es/ f?p=I000:I3I00:0::NO:I3100:PI3I00_COMMENT_ID:3297029:NO.

68 Informe de la Comisión de Encuesta constituida para examinar el cumplimiento por Myanmar del convenio sobre el trabajo forzoso, I930, Boletín Oficial 8I, I998, serie B, https://www. ilo.org/public/libdoc/ilo/P/og6,8/og6,8(Ig98-8I-serie-B-supl-especial).pdf.

69 Observación individual de la CEACR, 2018, https://www.ilo.org/dyn/normlex/es/ f?p=I000:IzI00:0::NO:IzI00:PizI00_COMMENT_ID:3958308:NO.

70 Discusión por la Comisión de Aplicación de Normas de la Conferencia, 20I7, https://www.ilo. org/dyn/normlex/es/f?p=I000:I3100:0::NO:IzI00:PI3I00_COMMENT_ID:3330959.

71 Observación individual de la CEACR, 2004, https://www.ilo.org/dyn/normlex/es/ f?p=I000:I3100:0::NO:I3100:PI3I00_COMMENT_ID:2243626.

72 Observación individual de la CEACR, 2003, https:/www.ilo.org/dyn/normlex/es/ f?p=I000:I3100:0::NO:I3100:PI3I00_COMMENT_ID:2230596.

73 Observación individual de la CEACR, 2014, https://www.ilo.org/dyn/normlex/es/ f?p=I000:IzI00:0::NO:IzI00:PizI00_COMMENT_ID:3i86g8z.

74 Observación individual de la CEACR, 2010, https://www.ilo.org/dyn/normlex/es/ f?p=I000:I3100:0::NO:I3100:PI3100_COMMENT_ID:233400g. 
En una mayoría de sus observaciones, la CEACR hizo hincapié no tanto en la falta de legislación tendente a prohibir el trabajo forzoso, sino más bien en su poca eficacia para terminar con su práctica factual, en muchos casos facilitada por el arraigo de costumbres ancestrales que resisten al paso de la ley, en otros por la poca severidad de las sanciones penales, y en muchos más por el poco celo de las autoridades públicas para aplicar la ley. Ejemplo de ello son las numerosas observaciones a Mauritania por la persistencia de la esclavitud con fuerte contenido étnico; a la India por la servidumbre por deudas o la esclavitud sexual de las niñas consagradas a las deidades (devadasi); a Haití por la esclavitud doméstica de los niños restavek, todas ya mencionadas en los párrafos anteriores; o a Myanmar por la requisa de comunidades enteras, por lo general pertenecientes a grupos étnicos minoritarios, por parte de las autoridades públicas con fines de efectuar trabajos de infraestructura, muchas veces en beneficio de empresas privadas, práctica cuya gravedad y persistencia fue tanta que mereció la constitución de una Comisión de Encuesta ${ }^{75}$. Este último caso se diferencia de los anteriores porque no hizo hincapié en la tolerancia de las autoridades públicas con respecto de prácticas ilegales, sino que incriminó directamente al Estado como principal autor y responsable de ellas, inclusive mediante legislación que las autorizaba o, peor aún, las organizaba. A pesar de algunos avances que se han logrado desde entonces, la CEACR aún continúa manifestando su "profunda preocupación” por la persistencia del trabajo forzoso en varias regiones de Myanmar ${ }^{76}$.

Merece también que mencionemos muchos otros casos en los que la CEACR formuló observaciones sobre leyes nacionales que en su opinión no estaban en conformidad con los Convenios 29 y 105. Figuran entre ellos la obligación de trabajar que imponen las llamadas "leyes de vagancia", el trabajo penitenciario y las penas de prisión que pueden conllevar trabajo forzoso por delitos de opinión, o por incitar o participar en huelgas, o por negativa a cumplir servicio civil $^{17}$.

Con respecto de la obligación de trabajar, la CEACR ha observado que figura en numerosas constituciones en las que el deber de trabajar aparece como una contrapartida del

75 “Trabajo forzoso en Myanmar (Birmania), Informe de la Comisión de Encuesta instituida en virtud del artículo 26 de la Constitución de la Organización Internacional del Trabajo para examinar la observancia por Myanmar del Convenio sobre el trabajo forzoso, I930 (núm. 29)", Organización Internacional del Trabajo, https:/www.ilo.org/public/spanish/standards/ relm/gb/docs/gb273/myanmar.htm.

Observación individual de la CEACR, 20I8, https://www.ilo.org/dyn/normlex/es/ f?p=I000:I3100:0::NO:I3100:PI3I00_COMMENT_ID:3957004.

77 Véase las observaciones individuales de la CEACR a Argelia, Bolivia, Botsuana, Burundi, Camboya, Camerún, Egipto, Eritrea, Indonesia, Libia, República Centroafricana, Kenia y Marruecos. 
derecho al trabajo. Este enunciado se ha considerado compatible con los Convenios 29 y 105 en la medida en que no se traduzca en disposiciones en virtud de las cuales se puedan imponer sanciones que conlleven la obligación de trabajar, como lo habían hecho las "leyes de vagos y maleantes" de varios países de América hispánica, en su mayor parte hoy derogadas o en desuetudo; o, más recientemente la ley relativa a las persona indigentes de 1989 en Singapur, en virtud de la cual puede exigirse a las personas indigentes, bajo sanciones penales, que residan en un hogar de asistencia social (artículos 3 y 16) y que ejecuten tareas acordes con sus aptitudes, ya sea con miras a encontrar un empleo para ellas fuera del hogar de asistencia, ya sea para contribuir a su mantenimiento en el hogar de asistencia social (artículo 13). En su observación publicada en 2011, la CEACR recordó una vez más que la imposición de un trabajo con arreglo a la Ley relativa a las Personas Indigentes de 1989 se encuentra dentro de la definición de "trabajo forzoso u obligatorio" en el artículo 2, párrafo 1 del Convenio $29^{78}$. La ley en cuestión debería por tanto enmendarse "de modo que disponga claramente que todo trabajo realizado en un hogar de asistencia social se realice voluntariamente, haciendo concordar la mencionada legislación con las disposiciones del Convenio". Queda claro que a juicio de la CEACR la libertad de trabajar implica también la de no trabajar.

Por su parte, el tema de la compatibilidad del trabajo penitenciario con lo que dispone el Convenio 29 suscita hoy bastante interés, pues es creciente el número de países que han autorizado o consideran autorizar el recurso al sector privado para la administración de sus prisiones, incluyendo la utilización de las personas detenidas como mano de obra con fines comerciales o industriales. De larga data, otros países han permitido el funcionamiento de talleres privados dentro de las prisiones, o la utilización de mano de obra penitenciaria fuera de ellas.

En su Estudio General de 2007, la CEACR subrayó que el trabajo o el servicio obligatorio exigido a una persona como consecuencia de una condena en un tribunal de justicia, es compatible con el Convenio 29 "solo si se reúnen dos condiciones, a saber: que el mencionado trabajo o servicio sea llevado a cabo con la supervisión y el control de una autoridad pública; y que la mencionada persona no sea cedida o puesta a disposición de particulares, compañías o personas jurídicas de carácter privado". Estas dos condiciones se deben aplicar de manera cumulativa, es decir, que el hecho de que el recluso permanezca todo el tiempo bajo la supervisión y el control de una autoridad pública no exime en sí mismo al Gobierno de cumplir con la segunda condición, a saber, que el individuo no sea "cedido o puesto a disposición de particulares, compañías o personas jurídicas de carácter privado". Estos principios han sido recordados en observaciones que la CEACR dirigió en sucesivos informes a los Gobiernos de Australia, Austria y Reino Unido con

78 Observación individual de la CEACR al Gobierno de Singapur, https:/www.ilo.org/dyn/normlex/es/f?p=I000:I3100:0::NO:I3100:PI3I00_COMMENT_ID:26g8182. 
motivo de regímenes penitenciarios que permiten la cesión de reclusos a empresas del sector privado que pueden utilizar su mano de obra en lugares de trabajo, tanto dentro como fuera de las prisiones. Añadiremos que un país como Estados Unidos indicó a la CEACR que no tiene intención de ratificar el Convenio 29, precisamente debido a la incidencia que podría tener en la situación de las prisiones americanas, ya que pudiera ser interpretado y aplicado de manera de limitar la medida en que el sector privado pueda involucrarse en el trabajo penitenciario ${ }^{79}$. Observemos, no obstante, que Canadá, otro país que tenía objeciones similares, ratificó el convenio en 2010.

Con respecto de Austria, la CEACR consideró que

el trabajo realizado por reclusos para empresas privadas solo puede seguir siendo compatible con la prohibición explícita del Convenio cuando existan las salvaguardias necesarias para garantizar que los reclusos afectados se ofrezcan voluntariamente, sin sujeción a la presión o a la amenaza de una pena cualquiera, como exige el artículo 2,1), del Convenio [...] En tal situación, el trabajo de los reclusos para empresas privadas no entra en el campo de aplicación del Convenio, puesto que no implica obligación alguna.

En concreto, la CEACR solicitó al Gobierno que adoptara las medidas necesarias para garantizar la observancia del Convenio, "como por ejemplo, disponer que todo recluso que trabaje para empresas privadas se ofrezca voluntariamente sin estar sujeto a la presión o a la amenaza de una sanción y, dadas sus condiciones de mano de obra cautiva, estando sujeto a garantías tales como los salarios y otras condiciones laborales que se aproximen a una relación de trabajo libre”. Además, consideró que

habida cuenta de la situación de cautividad, es necesario obtener el consentimiento formal de los reclusos para trabajar en empresas privadas, tanto dentro como fuera de las cárceles. Puesto que ese consentimiento es dado en un contexto de ausencia de libertad y con opciones limitadas, debería contarse con indicadores que autentiquen su consentimiento libre y con conocimiento de causa. De ellos, el más fiable es que las condiciones en las cuales se realice ese trabajo sean semejantes a las condiciones de una relación de trabajo libre, que incluyen los niveles de salarios (dejando margen para descuentos y cesiones), seguridad social, y seguridad y salud ocupacional ${ }^{80}$.

79 “Estudio general”, párrafo 28.

80 Observación individual de la CEACR, 20II, https://www.ilo.org/dyn/normlex/es/ f?p=I000:IzI00:0::NO:IzI00:PIzI00_COMMENT_ID:26g8IIय. 
Con respecto al Reino Unido, la CEACR expresó

la firme esperanza de que se adopten medidas para garantizar que se exija un consentimiento dado libremente e informado para el trabajo de los reclusos en las cárceles privatizadas, así como también en el caso del trabajo de los reclusos para empresas privadas, tanto dentro como fuera de los locales de la cárcel. Tal consentimiento "libre" e "informado" deberá ser certificado por condiciones de trabajo que se aproximen a una relación de trabajo libre, en lo que atañe a los niveles salariales (dejando un margen para descuentos y embargos), a la seguridad social y a la seguridad y salud en el trabajo [La CEACR] confía en que se adopten tales medidas, tanto en la ley como en la práctica, a efectos de otorgar a los reclusos que trabajan en instalaciones que funcionan privadamente y a otros reclusos que trabajan para empresas privadas, un estatuto legal con derechos y condiciones de empleo que sean compatibles con este instrumento básico de derechos humanos y en que el Gobierno se encuentre pronto en condiciones de informar acerca de los progresos realizados al respecto ${ }^{81}$.

El tercer caso, la imposición de sanciones penales que pueden conllevar trabajo obligatorio por el delito de opinión o por participación en huelgas ilegales, negativa a prestar servicio civil o a efectuar trabajos de interés general, han sido considerados por la CEACR en el marco de la aplicación del Convenio sobre la abolición del trabajo forzoso, de 1957 (núm. 105). Recordemos que este convenio prohíbe cualquier forma de trabajo forzoso $u$ obligatorio como sanción, medio de coerción o educación, medida de disciplina o castigo con respecto a las personas comprendidas en el ámbito del artículo 1, apartados a), c) y d). El valor añadido de este convenio con respecto al Convenio 29 consiste en que este último no prohíbe el trabajo forzoso cuando es resultado de una condena judicial que pudiera ser consecutiva, por ejemplo, a un delito de opinión, mientras que el Convenio 105 sí lo prohíbe. En contrapartida, ningưna disposición del Convenio 105 prohíbe la imposición de sanciones penales por los mismos hechos, siempre y cuando estas no conlleven la obligación de prestar trabajo forzoso ${ }^{82}$.

Ya en su Estudio General de 2007, la CEACR había tomado nota

con satisfacción de que en algunos países se han derogado las disposiciones en virtud de las cuales era posible aplicar sanciones penales que conllevaban trabajo obligatorio, para castigar actividades como las siguientes: diversas formas de expresión o de crítica de índole política; la difusión de publicaciones y materiales

81 Observación individual de la CEACR, 20II, https://www.ilo.org/dyn/normlex/es/

f?p=I000:I3100:0::NO:I3100:PI3100_COMMENT_ID:26g8r26.

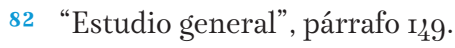


de propaganda contrarios al orden político establecido o destinados a vulnerar la soberanía nacional o debilitar el sentimiento nacional, o de información tendenciosa encaminada a menoscabar el prestigio del Estado o de las autoridades, diversos actos relacionados con actividades comunistas (como propagar la ideología comunista o pertenecer a una organización comunista, o asistir a una reunión comunista, etcétera); la divulgación de rumores y noticias falsas; y ciertos otros delitos en relación con la manifestación de opiniones. La Comisión también tomó nota "con satisfacción" de la derogación de disposiciones, cuya aplicación daría lugar a sanciones de prisión (incluida la obligación de trabajar), que prohíben la publicación de cualquier periódico, si se considera que así lo requiere el interés público ${ }^{83}$.

Resta que en numerosos países estas sanciones siguen existiendo ${ }^{84}$.

\section{PERSPECTIVAS DESDE ESTRASBURGO: CONVENIO EUROPEO DE DERECHOS HUMANOS Y TRIBUNAL EUROPEO DE DERECHOS HUMANOS}

El Convenio para la protección de los derechos humanos y las libertades fundamentales, más conocido por su nombre abreviado de Convenio Europeo de Derechos Humanos (CEDH) fue adoptado por los Estados Miembros del Consejo de Europa en 1950 y entró en vigor en septiembre de 1953. Tiene por objeto proteger los derechos humanos y las libertades fundamentales, cuyo respeto se asegura mediante el control jurisdiccional del Tribunal Europeo de Derechos Humanos (TEDH), al que es posible acudir por vía de recurso judicial en condiciones que examinaremos luego. Tanto el Consejo de Europa como el TEDH tienen su sede en Estrasburgo, Francia. El CEDH es jurídicamente vinculante para los 47 Estados miembros del Consejo de Europa.

En su redacción original, el CEDH se había dotado de dos órganos de aplicación, respectivamente la Comisión Europea de Derechos Humanos y el TEDH. Aparte de monitorear el cumplimiento del CEDH, la Comisión actuaba como filtro con respecto a las denuncias contra los Estados partes que pudieran ser sometidas por particulares cuyos derechos garantizados por el TEDH habían sido presuntamente violados. Sin embargo, con posterioridad a su entrada en vigor, el CEDH fue ampliado por varios protocolos, de los cuales aquí citaremos el Protocolo 11, adoptado en mayo de 1994 y vigente desde el primero de noviembre de 1998. Al tiempo que suprimió la Comisión, el Protocolo 11 confirió competencia al TEDH para conocer de manera directa de las demandas presentadas por cualquier persona física, organización no gubernamental o grupo de particulares que se considerara víctima de una violación por un Estado parte de los derechos reconocidos

83 Ibid., párrafo $5^{6} 6$.

84 Véase las observaciones individuales de la CEACR con respecto de Argelia, Bolivia, Botsuana, Burundi, Camboya, Camerún, Egipto, Eritrea, Indonesia, Libia, República Centroafricana, Kenia, Marruecos y Chile. 
en el CEDH o sus protocolos ${ }^{85}$, y siempre a condición que el interesado hubiera agotado los recursos disponibles a nivel interno y no se hubiera cumplido un plazo de seis meses a partir de la decisión interna definitiva.

El TEDH es un órgano permanente, integrado por un número de jueces igual al de Estados partes en el CEDH (actualmente 47). El cometido esencial del TEDH es constatar si un Estado parte ha incurrido en violación de algunos de los derechos garantizados por el CEDH y, en caso afirmativo, ordenar una reparación adecuada. Además de su gran peso moral, las sentencias son vinculantes para el Estado contra quien se dirigió el procedimiento y su cumplimiento es monitoreado por el Comité de Ministros del Consejo de Europa. El TEDH actúa en formación de juez único, en comités formados por tres jueces, en salas de siete jueces o en una Gran Sala de diecisiete jueces. Tanto la formación en juez único como en comités de tres jueces tienen por cometido examinar la admisibilidad de los recursos presentados por los particulares, mientras que las salas de siete jueces deciden sobre el fondo de los asuntos cuya admisibilidad ha sido declarada. A su vez, la Gran Sala conoce de los asuntos de grave importancia o cuando una Sala de siete jueces se hubiera inhibido en su favor o si la solución dada a una cuestión pudiera ser contradictoria con una sentencia dictada anteriormente por el TEDH. También incumbe a la Gran Sala la tarea de emitir opiniones consultivas acerca de la interpretación que debe darse al CEDH o sus protocolos.

Para dar una idea de la actividad del TEDH, conviene destacar que en 2018 recibió nada menos que 56.000 demandas, aun cuando es cierto que en su inmensa mayoría fueron desestimadas, casi siempre por no cumplir con uno o más de sus requisitos procesales. Resta que en el mismo año el TEDH pronunció 1.014 sentencias, de las cuales 14 fueron en Gran Sala, 463 en sala y 537 en comités de tres jueces ${ }^{86}$. Agreguemos que casi el $40 \%$ de las violaciones constatadas por el TEDH se refieren al artículo 6 del CEDH (derecho a un proceso equitativo), ya sea por la imparcialidad (17\%) o la duración (20\%) de los procedimientos. La segunda violación más frecuente se refiere al derecho a la libertad y la seguridad (artículo 5). En más del 15\% de los casos, el TEDH ha encontrado una violación grave del CEDH, en relación con el derecho a la vida o la prohibición de la tortura y los tratos inhumanos o degradantes (artículos 2 y 3 ).

85 Con anterioridad, el Protocolo 9 permitía el acceso de dichas personas al TEDH previo filtro de la Comisión. En virtud del Protocolo ir, el Protocolo 9 fue derogado y la Comisión suprimida, de modo que los particulares pueden acudir directamente al Tribunal.

86 "Rapport annuel Cour Européenne del droits de l'homme 20I8", Consejo de Europa, https:// www.echr.coe.int/Documents/Annual_report_20I8_FRA.pdf. 
El CEDH protege los siguientes derechos: i) derecho a la vida (artículo 2); ii) prohibición de la tortura (artículo 3); iii) prohibición de la esclavitud y el trabajo forzoso (artículo 4); iv) derecho a la libertad y a la seguridad (artículo 5); v) derecho a un proceso equitativo (artículo 6); vi) respeto de la vida privada y vida familiar (artículo 8); vii) libertad de pensamiento, conciencia y religión (artículo 9); viii) libertad de expresión (artículo 10); ix) derecho de reunión y de asociación (artículo 11); y x) prohibición de la discriminación, especialmente por razones de sexo, raza, color, lengua, religión, opiniones políticas u otras, origen nacional o social, pertenencia a una minoría nacional, fortuna, nacimiento o cualquier otra situación (artículo 14).

Los casos en los que se ha denunciado la violación del artículo 4 son comparativamente pocos pero significativos, por cuanto definen con claridad las obligaciones que incumben a un Estado parte con objeto de prevenir y reprimir cualquier práctica de trabajo forzoso, lo que incluye el tráfico de personas. Como veremos a continuación, en ningún caso de los que se presentan aquí se imputaron faltas directas al Estado, pero el TEDH sí halló que incumplía el artículo $4 \mathrm{CEDH}$, ya sea por la insuficiencia del marco legal, en particular por la ausencia de sanciones penales eficaces, por la duración excesiva de los procedimientos, o bien por la falta de celo con que las autoridades públicas o los fiscales diligenciaron las denuncias de las víctimas.

Siliadin con Francia ${ }^{87}$ es un caso que pone de relieve la cuestión de la servidumbre doméstica. La demandante, una niña togolesa de 18 años (15 años cuando fue llevada a Francia) había sido obligada a trabajar como empleada doméstica para una familia francesa de origen togolés durante varios años sin ser pagada, sin tener derecho a días de descanso, sin papeles en regla y bajo el temor de ser expulsada de Francia por su condición de inmigrante irregular. Con el apoyo del Comité contra la Esclavitud Moderna, una ONG francesa, la demandante inició un procedimiento judicial contra su empleadora, el que luego de diversas peripecias concluyó con el otorgamiento de una indemnización por daños y perjuicios, pero no hubo ninguna sanción penal.

El TEDH halló que el trato prodigado a la niña Siliadin no encajaba dentro de la definición de esclavitud, pero sí de servidumbre y de trabajo forzoso, habida cuenta de su situación de vulnerabilidad. El TEDH consideró que la legislación penal vigente en el momento de los hechos no había proporcionado a la solicitante una protección específica y eficaz contra el accionar del que había sido víctima. El TEDH concluyó que Francia no había cumplido con sus obligaciones dimanantes del artículo 4 y ordenó una reparación. Como consecuencia de este fallo, Francia enmendó su legislación penal para hacer más severa la represión de la servidumbre y el trabajo forzoso.

87 Sentencia del caso Siliadin con Francia, Tribunal Europeo de Derechos Humanos, rol 73316/or, 26 de julio 20I5, https://hudoc.echr.coe.int/eng\#\{\%22itemid\%22:[\%2200I-6g8gi\%22]\}. 
En Chowdury y otros con Grecia ${ }^{88}$, el TEDH se pronunció por primera vez sobre la explotación laboral de trabajadores migrantes. El caso se inició con una demanda de 42 inmigrantes de Bangladesh sin permiso de trabajo y en situación migratoria irregular, representados por varios abogados del Congreso Griego para los Refugiados. Los damnificados habían sido reclutados entre octubre de 2012 y febrero de 2013 para la recolección de fresas en una gran explotación agrícola, pero no habían sido pagados, los habían hecho trabajar en condiciones físicas extremas y eran alojados en barracones precarios bajo la vigilancia de guardias armados. Luego de que su situación fuera denunciada ante la justicia, los empleadores fueron imputados por el delito de tráfico de personas, pero el Tribunal local los absolvió y el fiscal no apeló la absolución ante el Tribunal de Casación. El asunto fue llevado entonces ante el TEDH, el que consideró que había existido violación del artículo 4 del CEDH por cuanto el Estado no había investigado lo suficiente los hechos, a pesar de que estaba informado de ellos a través de crónicas periodísticas. El TEDH observó que la explotación laboral constituye un aspecto del tráfico de personas en el sentido del Protocolo de Palermo y del Convenio del Consejo de Europa sobre la Lucha contra la Trata de Seres Humanos, y concluyó que Grecia había incumplido con su obligación de prevenir el tráfico de personas, proteger a las víctimas, conducir una investigación idónea y sancionar de forma penal a los responsables del tráfico.

En T.I. y otras con Grecia ${ }^{89}$, el TEDH abordó el tema de la trata de personas con fines de explotación sexual. Las demandantes, tres ciudadanas rusas, habían llegado a Grecia entre junio y octubre de 2003 con visados expedidos por el consulado de Grecia en Moscú. En septiembre de 2003, una de las demandantes fue arrestada por la policía por prostitución, y en estas circunstancias declaró que había sido forzada a prostituirse. En el mes siguiente se iniciaron procesamientos contra tres proxenetas, pero este procedimiento conoció muchísimas dilaciones. Recién en junio de 2011, casi ocho años después, el Tribunal de Apelaciones de Salónica condenó a dos de ellos a prisión de cinco años y diez meses por asociación con fines delictuales, proxenetismo y trata de seres humanos. El tercero fue absuelto.

En mayo de 2005, las demandantes también habían presentado una denuncia ante la fiscalía del tribunal correccional competente, alegando que los documentos utilizados para obtener sus visas contenían indicaciones falsas, y acusaron a los empleados del consulado y a las empresas involucradas de haber facilitado su viaje a Grecia. A consecuencia

88 Sentencia del caso Chowdury y otros con Grecia, Tribunal Europeo de Derechos Humanos, rol 2188//15, 30 de marzo 20I7, https://hudoc.echr.coe.int/eng\#\{\%22itemid\%22:[\%2200I-I7270I\%22]\}.

Sentencia del caso T.I. y otras con Grecia, Tribunal Europeo de Derechos Humanos, rol 403 II/IO, I8 de julio de 20I9, https://hudoc.echr.coe.int/eng\#\{\%22itemid\%22:[\%2200I-I9441:1\%22]\}. 
de esta denuncia, la Fiscalía inició procedimientos por trata de personas contra varios individuos, incluidos tres empleados del consulado griego en Moscú, Sin embargo, en febrero de 2016, casi nueve años después de esta denuncia, la Cámara de Acusación del Tribunal Penal puso fin a los procedimientos contra dos de ellos, considerando que los delitos denunciados habían prescrito. En cuanto al tercer imputado, consideró que no había indicaciones serias acerca de la comisión de los delitos alegados, motivo por el que la denuncia fue desestimada.

Llevado este asunto a la esfera del TEDH, este consideró que el marco legal bajo el cual se habían llevado a cabo los procedimientos había demostrado ser ineficiente e insuficiente para castigar a los traficantes y garantizar la prevención efectiva de trata de seres humanos. El TEDH también determinó que las autoridades competentes no se ocuparon del caso con el nivel de diligencia requerido por el artículo \& CEDH, por lo que decidió que Grecia había incurrido en violación del artículo y lo condenó a indemnizar a las tres víctimas de trata.

\section{PERSPECTIVAS DESDE SAN JOSÉ: CORTE INTERAMERICANA DE DERECHOS HUMANOS Y EL CASO HACIENDA BRASIL VERDE}

El sistema interamericano de derechos humanos se articula en torno a la Convención Americana sobre Derechos Humanos (CADH), de 1969, en vigor desde 1978, también conocida como Pacto de San José, y su Protocolo en materia de derechos económicos, sociales y culturales, conocido como Protocolo de San Salvador, de 1988. Ambos instrumentos han sido adoptados en el marco de la Organización de Estados Americanos (OEA) y solo vinculan a aquellos Estados que, además de ser miembros de la OEA, han depositado sus respectivos instrumentos de ratificación o de aceptación. La CADH ha sido ratificada por todos los países de América Latina miembros de la OEA, pero no lo ha sido por Estados Unidos, Canadá, ni tampoco por varios países del Caribe de habla inglesa ${ }^{90}$.

La CADH enuncia un listado de derechos humanos que pertenecen en su mayor parte al dominio de los derechos civiles y políticos. Estos incluyen el derecho a la vida (artículo 4), a la integridad personal (artículo 5), prohibición de la esclavitud y servidumbre (artículo 6), derecho a la libertad personal (artículo 7), garantías judiciales (artículo 8), principio de legalidad y no retroactividad (artículo 9), derecho a indemnización (artículo 10), protección de la honra y de la dignidad (artículo 11), libertad de conciencia y de religión (artículo 12), libertad de pensamiento y de expresión (artículo 13), derecho de rectificación o respuesta (artículo 14), derecho de reunión (artículo 15), libertad de asociación (artículo 16), protección a la familia (artículo 17), derecho al nombre (artículo 18), derechos del niño (artículo 19), derecho a la nacionalidad (artículo 20), derecho a la propiedad privada

90 El ro de septiembre de 20I3, la CADH fue denunciada por la República Bolivariana de Venezuela, denuncia que fue dejada sin efecto por un Acuerdo de la Asamblea Nacional del i5 de mayo de 20I9. 
(artículo 21), derecho de circulación y de residencia (artículo 22), derechos políticos (artículo 23), igualdad ante la ley (artículo 24) y protección judicial (artículo 25). La CADH pone a cargo de los Estados partes los deberes fundamentales de respeto y de garantía de estos derechos.

La importancia de la CADH en el sistema americano de derechos humanos radica, en primer lugar, en las facultades de monitoreo sistemático que han sido conferidas a la Comisión Interamericana de Derechos Humanos, y, en segundo lugar, en el control jurisdiccional por la Corte Interamericana de Derechos Humanos. La Comisión tiene su sede en Washington; está integrada por siete miembros elegidos a título personal por la Asamblea General de la OEA, todos de diferente nacionalidad, quienes deben ser personas de alta autoridad moral y reconocida versación en materia de derechos humanos. Su primer cometido consiste en monitorear la manera como los Estados partes dan cumplimiento a sus obligaciones dimanantes de la ratificación de la CADH. Pero además, la Comisión ofrece la "puerta de entrada" para que los particulares puedan presentar denuncias de violación de los derechos garantizados por la $\mathrm{CADH}$ por los Estados partes. Esta facultad dimana del artículo 44 de la CADH, que dispone que "cualquier persona, o entidad no gubernamental legalmente reconocida en uno o más Estados miembros de la Organización, puede presentar a la Comisión peticiones que contengan denuncias o quejas de violación de esta Convención por un Estado parte". Vale decir que en el sistema americano de derechos humanos solamente la Comisión, no los particulares, puede elevar un asunto ante la Corte (ello sin perjuicio de la facultad que tiene un Estado de ir contra otro Estado si los dos son partes en la CADH).

A semejanza del Convenio Europeo de Derechos Humanos, estas peticiones establecen como condición de exigibilidad, en primer lugar, que se hayan interpuesto y agotado los recursos de jurisdicción interna; y en segundo, que no hayan transcurrido más de seis meses a partir de la fecha en que el presunto lesionado en sus derechos haya sido notificado de la decisión definitiva. Sin embargo, estas condiciones dejarían de ser exigidas cuando no existe en la legislación interna del Estado de que se trata el debido proceso legal para la protección del derecho o derechos que se alega han sido violados, no se ha permitido a la presunta víctima el acceso a los recursos de la jurisdicción interna, haya sido impedida de agotarlos, o ha habido retardo injustificado en la decisión sobre los mencionados recursos (artículo 46). El procedimiento judicial que establece la CADH es por lo tanto comparable al que existía en el sistema del Convenio Europeo de Derechos Humanos antes de la entrada en vigor de su Protocolo 11.

Por su parte, la Corte IDH es un cuerpo colegiado integrado por siete jueces designados por la Asamblea General de la OEA por votación secreta. El mandato de los jueces es de seis años y pueden ser reelectos una sola vez. Tiene su sede en San José de Costa Rica. De los 35 Estados miembros de la OEA, 20 han reconocido la competencia contenciosa 
de la Corte $^{91}$. A diferencia del TEDH, la Corte IDH no funciona de manera permanente; por ejemplo, en 2018 celebró ocho períodos de sesiones ordinarias y uno de extraordinarias $^{92}$. Por ese mismo motivo, su producción de sentencias es baja si se la compara con el TEDH. Así, en 2018 emitió 28 sentencias y una opinión consultiva y, no obstante, ese fue el año en el que emitió su mayor número de sentencias ${ }^{93}$. Agregaremos que las sentencias de la Corte IDH son finales, no son susceptibles de recurso excepto de interpretación o aclaración y, en caso de ser condenatorias, pueden ser ejecutadas en el respectivo país mediante el procedimiento de ejecución de sentencias contra el Estado.

Trabajadores de la Hacienda Brasil Verde con Brasil ${ }^{94}$ es el primer caso contencioso resuelto por la Corte IDH relacionado con la aplicación del artículo 6 CADH, que prohíbe la esclavitud, servidumbre y el trabajo forzoso. Su gran importancia deriva del hecho de que la Corte IDH aproximó la noción de trabajo forzoso del Convenio 29 de OIT y de muchos otros instrumentos internacionales, en particular la Convención suplementaria de 1956, a la noción de "esclavitud" de la Convención de 1926, considerando que esta es una noción evolutiva que va más allá del "derecho de propiedad" para comprender también a algunos de sus atributos que han sido caracterizados como "formas modernas de esclavitud". Entre estos atributos, la Corte IDH identificó: i) restricción o control de la autonomía individual; ii) pérdida o restricción de la libertad de movimiento de una persona; iii) la obtención de un provecho por parte del perpetrador; iv) la ausencia de consentimiento o de libre albedrío de la víctima, o su imposibilidad o irrelevancia debido a la amenaza de uso de la violencia u otras formas de coerción, el miedo de violencia, el engaño o las falsas promesas; v) el uso de violencia física o psicológica; vi) la posición de vulnerabilidad de la víctima; vii) la detención o cautiverio; y viii) la explotación ${ }^{95}$.

La Corte IDH también consideró que la trata de personas debía incluirse dentro de las conductas asimilables a la esclavitud moderna ${ }^{96}$. Además, subrayó que la prohibición de la esclavitud es una norma imperativa del derecho internacional (ius cogens), y conlleva

91 Estos Estados son: Argentina, Barbados, Bolivia, Brasil, Chile, Colombia, Costa Rica, Ecuador, El Salvador, Guatemala, Haití, Honduras, México, Nicaragua, Panamá, Paraguay, Perú, República Dominicana, Surinam y Uruguay.

92 “Informe anual 20I8”, Corte Interamericana de Derechos Humanos, http://www.corteidh. or.cr/tablas/informezor8/espanol.pdf.

93 Ibidem.

94 Sentencia del caso Trabajadores de la Hacienda Brasil Verde con Brasil, Corte IDH, 20 de octubre de 20I6, http://www.corteidh.or.cr/docs/casos/articulos/seriec_3I8_esp.pdf.

95 Trabajadores de la Hacienda Brasil Verde con Brasil, párrafo $27^{2}$.

96 Ibid, párrafo 289 . 
obligaciones erga omnes según la Corte Internacional de Justicia. En ese sentido, recordó que se ha incluido la esclavitud como delito de lesa humanidad respecto de los cuales los tribunales penales internacionales tienen competencia, como en su momento ya la habían tenido en virtud de los estatutos del Tribunal Militar Internacional de Núremberg de 1945, y del Tribunal Militar Internacional de Tokio de 1946, sin hablar de los diferentes tribunales penales internacionales constituidos para juzgar los crímenes de lesa humanidad en la antigua Yugoslavia en 1993, Ruanda en 1994 y Sierra Leona en 2000, y, por último, en el Estatuto del TPI de Roma, en 1998. Este último ha tipificado a la esclavitud como crimen de lesa humanidad y definió la esclavitud como "el ejercicio de los atributos del derecho de propiedad sobre una persona, o de algunos de ellos, incluido el ejercicio de esos atributos en el tráfico de personas, en particular mujeres y niños”. Finalmente, a semejanza de lo ya decidido por el TEDH, la Corte IDH consideró que el artículo 6 de la CADH no solamente obliga a prohibir la esclavitud en sus diversas formas, sino que además obliga a los Estados partes a tomar todas las medidas necesarias para prevenir la ocurrencia de prácticas de trabajo esclavo o asimilables.

Este caso fue sometido a la Corte IDH el 4 de marzo de 2015 por la Comisión Interamericana de Derechos Humanos. Se relaciona con prácticas de trabajo forzoso y servidumbre por deudas en la Hacienda Brasil Verde, ubicada en el estado de Pará. Los hechos del caso se enmarcaron en un contexto en el que decenas de miles de trabajadores, mayormente de los estados del nordeste de Brasil, son sometidos a trabajo esclavo. Además, la Comisión alegó que los trabajadores que lograron huir de la Hacienda Brasil Verde declararon sobre la existencia de amenazas de muerte en caso de abandonar la hacienda, el impedimento de salir libremente, la falta de salario o la existencia de un salario ínfimo, el endeudamiento con el propietario, la falta de vivienda, alimentación y salud dignas. La Comisión añadió que la persistencia de esta situación sería presuntamente atribuible al Estado, pues tuvo conocimiento de la existencia de estas prácticas en general y en específico en la Hacienda Brasil Verde desde 1989, y a pesar de dicho conocimiento no había adoptado las medidas razonables de prevención y respuesta, ni ofrecido a las presuntas víctimas un recurso judicial efectivo para la protección de sus derechos, la sanción de los responsables y la obtención de una reparación. Finalmente, se alegó la responsabilidad internacional del Estado por la desaparición de dos adolescentes, la cual había sido denunciada ante las autoridades estatales el 21 de diciembre de 1988, sin que presuntamente se hubieran adoptado medidas efectivas para dar con su paradero.

En efecto, los hechos delictivos imputados a los responsables de la Hacienda Brasil Verde no solo eran gravísimos, sino además eran conocidos de larga data por las autoridades públicas. En 1996, el Grupo Móvil de Fiscalización del Ministerio del Trabajo (MPT) había fiscalizado la Hacienda Brasil Verde y determinado la existencia de irregularidades como la falta de registro de los empleados y condiciones contrarias a las disposiciones laborales. En 1997, dos trabajadores denunciaron ante la Policía Federal de Pará haber trabajado y escapado de la Hacienda. El primero manifestó que un reclutador ("gato" en el lenguaje 
local) lo había contratado y que, al llegar a la Hacienda, ya debía dinero por hospedaje y utensilios. Ambos declararon que los trabajadores eran amenazados de muerte en caso de denuncia o fuga, y que eran escondidos durante las fiscalizaciones. A partir de estas declaraciones, el Grupo Móvil hizo una nueva fiscalización el 15 de marzo de 2000 y concluyó que: i) los trabajadores eran albergados en cobertizos cubiertos de plástico y paja con una total falta de higiene; ii) varios trabajadores eran portadores de enfermedades de la piel, no recibían atención médica y el agua no era apta para el consumo; iii) todos los trabajadores habían sufrido amenazas, inclusive con armas de fuego, y iv) los trabajadores declararon no poder salir de la hacienda. En ocasión de este último, operativo el Grupo Móvil rescató a 85 trabajadores.

Ya con anterioridad, el Ministerio Público Federal (MPF) había presentado una denuncia contra el "gato" y el gerenciador de la hacienda por los delitos de reducción a trabajo esclavo, atentado contra la libertad del trabajo y tráfico de personas, y contra el propietario de la hacienda por frustrar derechos laborales. No obstante ello, en 1999, la justicia federal autorizó la suspensión condicional por dos años del proceso contra el propietario de la hacienda, a cambio de la entrega de seis canastas básicas a una entidad de beneficencia. En 2001, en relación con los otros dos denunciados, el juez federal declaró su incompetencia para juzgar el proceso, por lo que los autos se enviaron a la justicia estadual, la cual a su vez se declaró incompetente en 2004. En 2007, el Superior Tribunal de Justicia decidió que la jurisdicción competente para el delito de trabajo esclavo era la federal. En 2008, se declaró extinta la acción penal.

Como resultado de la segunda fiscalización, en marzo de 2000 el Ministerio Público presentó una acción civil contra el propietario de la hacienda destacándose que podía concluirse que: i) la Hacienda Brasil Verde mantenía a los trabajadores en un sistema de cárcel privada; ii) quedaba caracterizado el trabajo en régimen de esclavitud, y iii) la situación se agravaba al tratarse de trabajadores rurales, analfabetos y sin ninguna instrucción, quienes habían sido sometidos a condiciones de vida degradantes. En julio de 2000 se llevó a cabo la audiencia, durante la cual el acusado se comprometió a no emplear a trabajadores en régimen de esclavitud y a mejorar las condiciones de estancia bajo pena de multa. En agosto del mismo año el procedimiento fue archivado.

Ya para entonces el caso había sido presentado ante la Comisión Interamericana de Derechos Humanos (noviembre de 1998) por la Comisión Pastoral de la Tierra y el Centro para la Justicia y el Derecho Internacional (CEJIL Brasil). Luego del trámite correspondiente, con intervención del Gobierno brasileño, la Comisión lo remitió a la Corte IDH (marzo de 2015). En su escrito de presentación, la Comisión ${ }^{97}$ declaró que "esta situación es atri-

97 Caso Trabajadores de la Hacienda Brasil Verde con Brasil, escrito de presentación presentado por Emilio Álvarez Icaza, secretario ejecutivo del Centro por la Justicia y el Derecho Internacional, 4 de marzo de 20I5, http://www.oas.org/es/cidh/decisiones/corte/20I5/12066NdeRes. pdf. 
buible internacionalmente al Estado de Brasil, pues tuvo conocimiento de la existencia de estas prácticas en general y específicamente en la Fazenda Brasil Verde desde al menos 1989”. La Comisión consideró que, a pesar de este conocimiento, el Estado no adoptó medidas razonables de prevención y respuesta, ni ofreció a las víctimas un procedimiento judicial efectivo para la protección de sus derechos, la sanción de los responsables y la obtención de una reparación. La Comisión también analizó el caso a la luz del principio de no discriminación.

En su decisión, la Corte IDH consideró probado que los trabajadores rescatados de la Hacienda Brasil Verde se hallaban en una situación que sobrepasaba los extremos de servidumbre por deuda y trabajo forzoso para llegar a configurar los elementos más estrictos de la definición de esclavitud, en particular: i) los trabajadores se encontraban sometidos al efectivo control de los gatos, gerentes, guardias armados de la Hacienda, y en definitiva también de su propietario; ii) de forma tal que se restringía su autonomía y libertad individuales; iii) sin su libre consentimiento; iv) a través de amenazas, violencia física y psicológica; v) para explotar su trabajo forzoso en condiciones inhumanas. Asimismo, considerando que los trabajadores habían sido reclutados mediante fraude, engaño y falsas promesas desde las regiones más pobres del país, sobre todo para haciendas de los estados de Maranhão, Mato Grosso, Pará y Tocantins, la Corte IDH consideró probado que también habían sido víctimas de la trata de personas. En sus conclusiones, la Corte IDH declaró:

Por todo lo anterior, Brasil no demostró haber adoptado, respecto del presente caso y al momento de los hechos, las medidas específicas, conforme a las circunstancias ya conocidas de trabajadores en situación de esclavitud y de denuncias concretas contra la Hacienda Brasil Verde, para prevenir la ocurrencia de la violación al artículo 6.1 constatada en el presente caso. El Estado no actuó con prontitud dentro de las primeras horas y días luego de la denuncia de esclavitud y violencia realizada por $\mathrm{NN}$ con gran sacrificio y riesgo personal, dejando perder horas y días valiosos. En el período entre la denuncia y la inspección, el Estado no logró coordinar la participación activa de la Policía Federal en la referida inspección más allá de la función de protección del equipo del Ministerio del Trabajo. Todo esto demuestra que el Estado no actuó con la debida diligencia requerida para prevenir adecuadamente la forma contemporánea de esclavitud constatada en el presente caso y que no actuó como razonablemente era de esperarse de acuerdo con las circunstancias del caso para poner fin a ese tipo de violación. Este incumplimiento del deber de garantía es particularmente serio debido al contexto conocido por el Estado y a las obligaciones impuestas en virtud del artículo 6.1 de la Convención Americana y específicamente derivadas del carácter de ius cogens de esta prohibición. 
La Corte IDH ordenó reparaciones de un orden de US\$ 30.000 a US\$ 40.000 en favor de cada una de las víctimas.

\section{CONSIDERACIONES FINALES}

Como lo hemos visto, aún en pleno siglo XXI - si bien se han logrado considerables progresos formales y legales- la erradicación del trabajo forzoso es un objetivo aún muy distante. Peor aún, según datos de la propia OIT, la cantidad de personas en situación de trabajo forzoso no solo no ha disminuido, sino que podría haber aumentado. No menos grave, más de la mitad de las víctimas de las prácticas de trabajo forzoso y trata de personas son mujeres y niñas.

La actualidad e importancia de este fenómeno no debe ser subestimada, y sin embargo a menudo lo es. Conviene entonces que nos preguntemos, primero, cuáles son los motivos por lo que los esfuerzos para erradicar el trabajo forzoso avanzan a pasos tan lentos, y luego, qué dirección deberían tomar esos esfuerzos para que puedan rendir sus mejores frutos en un plazo razonablemente breve.

Para ello, debemos reconocer que el trabajo forzoso en sus diversos aspectos es un fenómeno multifacético y cambiante. En las primeras décadas del siglo XX, los instrumentos internacionales que abordaron esta cuestión, en particular la Convención sobre la Esclavitud de 1926 y el Convenio de la OIT sobre el trabajo forzoso, de 1930 (núm. 29), centraron su preocupación en los abusos emergentes del colonialismo, que hacía utilización sistemática y excesiva de mano de obra nativa con fines de desarrollo económico. Luego, en el período de entreguerras y durante la Segunda Guerra Mundial, varios Estados emplearon mano de obra servil de forma masiva, y más adelante, el trabajo forzoso fue utilizado con fines de "reeducación política" o con otras finalidades de las que el Convenio 105 de OIT ofrece una lista bastante detallada. En todos estos casos, la normativa internacional partió de la asunción de que el Estado tenía responsabilidad directa en muchas de las diferentes prácticas de trabajo forzoso. Sin embargo, hoy día, con pocas excepciones (de las cuales Myanmar es la más notoria), el trabajo forzoso no es obra directa del Estado sino de actores privados, como pueden serlo señores feudales que explotan a personas sometidas a servidumbre por deudas, propietarios de talleres clandestinos o semiclandestinos, jefes o jefas de hogares de familia que emplean trabajadores domésticos en condiciones no muy lejanas de la esclavitud, o traficantes locales o internacionales de seres humanos, a menudo relacionados con redes de delincuencia organizada trasnacional.

Esto desde luego no exime de responsabilidad al Estado, sino que lo convoca a una actitud más proactiva de cara a las nuevas formas que ha venido tomando las diversas prácticas de trabajo forzoso. La adopción de legislación que prohíba y reprima aquellas prácticas, incluyendo la trata o tráfico de personas, es un primer paso, y en la realidad muchos Estados lo han dado. Sin embargo, esto de nada sirve si dicha legislación no es aplicada a 
conciencia y, de hecho, existen más que sobrados casos que permiten inferir que muy a menudo el Estado, incluyendo a sus órganos judiciales, la aplica cuando menos a desgano. Lo mismo puede decirse de la tarea de prevención que incumbe al Estado, tarea que exige la puesta a disposición de medios y recursos idóneos tanto "hacia arriba" para proteger a las personas susceptibles de ser víctimas del trabajo forzoso antes de que esto suceda, como "hacia abajo" para rescatarlas de la situación servil en la que han caído y eventualmente asegurarles protección, reparación y readaptación. La Recomendación de la OIT sobre el trabajo forzoso (medidas complementarias), 2014 (núm. 203) ofrece lineamientos muy útiles en ese sentido.

Sin embargo, bastante poco puede lograrse si no se avanza aún más "hacia arriba" hasta tocar los factores estructurales que explican la persistencia de un fenómeno que suscita tanto repudio institucional y legal. La pobreza y la falta de educación, y junto con ellas la vulnerabilidad son rasgos comunes a una inmensa mayoría de aquellas personas que día a día son víctimas del trabajo forzoso. A ello se añade la para nada infrecuente percepción social de que aquellas víctimas no merecen la atención del Estado ni de la sociedad en general, habida cuenta de que muchas veces son migrantes en situación irregular y otras pertenecen a los escalones más bajos de la sociedad de un país a quienes el resto de la sociedad mira con indiferencia, si no con desprecio. De ahí tendremos que el fenómeno del trabajo forzoso comporta también un ingrediente muy fuerte de exclusión social y discriminación.

Como se advierte, para terminar con el trabajo forzoso no alcanza con "educar al Estado" para que cumpla de buena fe con sus compromisos internacionales. También es indispensable que la sociedad en su conjunto tenga mayor empatía con aquellos que tienen menos y sufren más. 


\section{BIBLIOGRAFÍA}

- Goudal, Jean. "The Question of Forced Labour before the International Labour Conference”. International Labour Review 19, n. ${ }^{\circ} 5$ (1929).

- OIT, Organización Internacional del Trabajo y Walk Free Foundation. Estimaciones mundiales sobre la esclavitud moderna: Trabajo forzoso y matrimonio forzoso. Ginebra: 8.7 Alliance, 2017. 